https://helda.helsinki.fi

\title{
pÿGet some respect buy organic foods! When everyday consumer choices serve as prosocial status signaling
}

\section{Luomala, Harri}

2020-02-01

Luomala , H , Puska , P , Lähdesmäki , M , Siltaoja , M \& Kurki , S 2020 , ' Get some respect pÿ buy organic foods! When everyday consumer choices serve as prosocial status signaling ' , Appetite , vol. 145 , 104492 . https://doi.org/10.1016/j.appet.2019.104492

http://hdl.handle.net/10138/335563

https://doi.org/10.1016/j.appet.2019.104492

cc_by_nc_nd

acceptedVersion

Downloaded from Helda, University of Helsinki institutional repository.

This is an electronic reprint of the original article.

This reprint may differ from the original in pagination and typographic detail.

Please cite the original version. 


\section{Journal Pre-proof}

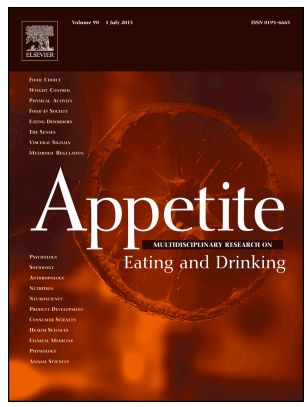

Get some respect - buy organic foods! When everyday consumer choices serve as prosocial status signaling

Harri Luomala, Petteri Puska, Merja Lähdesmäki, Marjo Siltaoja, Sami Kurki

PII:

S0195-6663(18)31806-3

DOI:

https://doi.org/10.1016/j.appet.2019.104492

Reference: $\quad$ APPET 104492

To appear in: Appetite

Received Date: 14 December 2018

Revised Date: 30 August 2019

Accepted Date: 13 October 2019

Please cite this article as: Luomala H., Puska P., Lähdesmäki M., Siltaoja M. \& Kurki S., Get some respect - buy organic foods! When everyday consumer choices serve as prosocial status signaling, Appetite (2019), doi: https://doi.org/10.1016/j.appet.2019.104492.

This is a PDF file of an article that has undergone enhancements after acceptance, such as the addition of a cover page and metadata, and formatting for readability, but it is not yet the definitive version of record. This version will undergo additional copyediting, typesetting and review before it is published in its final form, but we are providing this version to give early visibility of the article. Please note that, during the production process, errors may be discovered which could affect the content, and all legal disclaimers that apply to the journal pertain.

(C) 2019 Published by Elsevier Ltd. 


\title{
Get some respect - buy organic foods!
}

\section{When everyday consumer choices serve as prosocial status signaling}

\begin{abstract}
Status considerations have recently been linked to prosocial behaviors. This research shows that even everyday consumer behaviors such as favoring organic foods serve as prosocial status signaling. Key ideas from the continuum model of consumer impression formation and the theories of costly signaling and symbolic consumption are synthetized to make sense of this phenomenon. Two web-surveys $(\mathrm{Ns}=187,259)$ and a field study $(\mathrm{N}=336)$ following experimental designs are conducted. This approach allows the analysis of both the more and less conscious reactions of consumers. Study 1 shows that the image of consumers favoring organic product versions is marked by characteristics consistent with prosocial status signaling. Study 2 replicates these findings with another sample and a wider range of products and demonstrate that observers' conservative values influence the image formed of organic food users. Study 3 establishes that similar image effects also emerge through a less conscious formation process and that they extend to how organic food users are socially treated. This research advances the current understanding concerning the interlinkages between organic food usage, prosocial status signaling, consumer impressions and reputation management. Substantively, the studies provide novel compelling empirical evidence for the ability of non-luxurious everyday consumer behaviors to qualify as prosocial status signaling. Conceptually, the integration of evolutionary and sociocultural perspectives represents a major contribution. More specifically, this research yields new understanding as regards the role of individual variation in sensing and interpreting status symbols.
\end{abstract}

Keywords: Food; Consumer image; Costly signaling; Status; Organic; Prosociality 
Get some respect - buy organic foods!

\section{When everyday consumer choices serve as prosocial status signaling}

\section{Introduction}

Prosocial behaviors such as civic participation, volunteering, donating money, or buying products that benefit a good cause are of great interest to consumers and marketers alike (Cavanaugh, Bettman, \& Luce, 2015). Modern consumers are willing to pay for prosocial product attributes in the name of impression management (Delgado, Harriger, \& Khanna, 2015). To illustrate, when asked to choose between fair trade and less ethical coffee in the presence of an opposite-sex observer, roughly $60 \%$ of consumers chose the fair trade option, even though it was $10 \%$ more expensive than the less ethical option - the preferred choice of the remaining $40 \%$ of consumers (Shang \& Peloza, 2016). Intriguingly, status considerations have recently been linked to prosocial (including green) behaviors to an increasing extent (Elliot, 2013; Sexton \& Sexton, 2014).

From the status-management perspective, the puzzle of why people behave prosocially or altruistically toward non-kin individuals has been explained in terms of the evolutionary theory of costly signaling or CST (Bereczkei, Birkas, \& Kerekes, 2010). It states that altruistically motivated actions enable individuals to gain social recognition and preferential treatment in their groups (Soler, 2012). Thus, individuals who engage in altruistic acts actually may serve their own interests by demonstrating desirable characteristics such as conscientiousness and intelligence to others (Lee, Ko, \& Megehee, 2015). For the signal to be reliable, it must be costly in terms of energy use, time expenditure and risk potential. Thus, displays of public self-sacrifice 
can be associated with status, as they tell about the signalers' willingness and ability to incur costs for the common good, even though they can simultaneously accrue fitness benefits (e.g. reproductive success, resource control, rival deference) for themselves through this behavior (Bliege Bird \& Smith, 2005). Currently, status is regarded as a fundamental human motive that often involves triggering of automatic and nonconscious mental processes and behavioral responses (Anderson, Hildreth, \& Howland, 2015).

Reputational, social and status drives, which often exert their influence more subtly, have received limited attention as shapers of organic food consumption (Costa, Zepeda, \& Sirieix, 2014; Rana \& Paul, 2017), even though the notion of symbolic or conspicuous consumption has been around for a long time (see, e.g., Kim \& Jang, 2017). Yet, nonconscious motivations can be highly influential in the food realm as well (Berger \& Shiv, 2011; Dubois, Rucker, \& Galinsky, 2012). Unsurprisingly, when asked directly (e.g. in surveys necessitating conscious processing), consumers typically express a preference for organic foods because they are healthy, safe, goodtasting, ecological and animal-friendly (see, e.g., Kareklas, Carlson, \& Muehling, 2014; Bryla, 2016) - and downplay status motivations. Recent experimental research offers contrary evidence: Priming of status motivations can lead not only to increased choice preferences for organic foods, but also to heightened taste pleasantness ratings and experiences of joy and hopefulness after eating a food sample believed to be organic (Puska, Kurki, Lähdesmäki, Siltaoja, \& Luomala, 2018).

Logically, choice motivations reflect the symbolic meanings consumers attach to food. For example, Puska and Luomala (2016) show how different reasons for pursuing health can create qualitatively different images of food products in consumers' minds. Correspondingly, the typical organic food choice motivations cited above can invoke symbolic meanings of well- 
being, security, pleasure, universalism, ethicality and status. They key idea of symbolic consumption theories (e.g., the notions of meaning transfer and extended self) encompasses consumers' use of the symbolic meanings embodied in products to construct, sustain, and express their selves/identity and to locate them in society (Larsen, Lawson, \& Todd, 2010). In turn, these meanings can be transferred through socially constructed conventions and interactions to organic food users by observing individuals (cf. Vartanian, Herman, \& Polivy, 2007; Vartanian, 2015). Many factors such as observer characteristics, situational context and sociocultural setting can influence whether this meaning transfer occurs partially vs. fully or consciously vs. nonconsciously (Fiske, Lin, \& Neuberg, 1999; Sanders, 2010; Sexton \& Sexton, 2014). In any case, consumers tend to judge themselves and others in relation to the underlying reasons and emerging meanings that are believed to drive their purchase and ownership of goods (cf. Weiss \& Venkataramani Johar, 2016) - establishing the linkage from choice motivations, through symbolic meanings to perception of organic food users by observers.

The costly signaling theory has so far been applied to explore how signal receivers perceive and treat signal senders in the context of luxury brands (Nelissen \& Meijers, 2011; Lee et al., 2015). Even though the CST can also be used to explain altruism (Griskevicius, Tybur, \& Van den Bergh, 2010, p. 394), the extant studies still focus on egoistically motivated conspicuous consumer behaviors (Han, Nunes, \& Dréze, 2010). In other words, in effect, they stick to addressing more conventional status signaling (Wang \& Griskevicius, 2014). The thought of status signaling occurring through altruistically motivated conspicuous prosocial product choices (e.g., TOMS shoes) is new and contradictory (Berman, Levine, Barasch, \& Small, 2015).

The present enquiry embarks on this novel research strand and fuses the logic of the continuum model of consumer impression formation with ideas from the costly signaling and 
symbolic consumption conceptualizations. This multi-theoretical approach employing three empirical studies contributes to the current status signaling literature in two ways. First, this research substantiates the ability of non-luxurious everyday consumer behaviors such as favoring organic food to act as prosocial status signaling. This inquiry extends Griskevicius et al.'s (2010) seminal work on conspicuous conservation in several ways: by focusing on signal reception instead of sending; by investigating consumer perishables instead of durables; by drawing on a broader set of theories instead of only one (CST); by measuring consumers' images and social treatment as dependent variables (DVs) instead of choices; and by applying both explicit and implicit methods instead of only one (implicit priming of status motives).

Second, the moderators of the process whereby consumers form an image of organic food users have so far been poorly recognized, conceptualized and empirically verified. To illustrate, Brooks and Wilson (2015) proposed without solid theorizing that observers' characteristics such as "environmental orientation" (operationalized as majoring, i.e., in ecology vs. accounting) affect the perceived status of a person who is believed to be seeking to reduce consumption (alternative vehicle for prosocial status signaling); their results were nonsignificant. To produce new knowledge, this research links observers' certain personal values, both deductively and empirically, to the image conveyed by organic food users. More generally then, this study enriches the understanding of how individual variation within observers affects the way they sense and interpret (prosocial) status symbols - a theme that has been afforded a high priority on future research agendas (Anderson et al., 2015).

Together with fair trade and local food choices, favoring organic food represents a form of prosocial consumption (Ross \& Kapitan, 2018). In North America and Europe, organic foods are a multi-billion business that keeps on growing (Schrank \& Running, 2018). Thus, the concept of 
prosocial status signaling also offers interesting possibilities to marketers and policy-makers to promote sustainability. It can give new insights for manufacturers of prosocial products as regards to how to utilize consumers' reputational efforts (sending and interpreting image messages) in achieving, for example, attitudinal and behavioral change more effectively. Societally, the consideration of the evolutionary processes involved in prosocial status signaling can help in harnessing them to lessen environmental problems (Griskevicius, Cantú, \& van Vugt, 2012).

The following section presents the conceptual underpinnings for this research and derives three hypotheses. Next, Study 1 reports results indicating that the image of consumers who are believed to favor organic foods converges with the key features of a prosocial status signal. Study 2 replicates these findings with another sample and wider range of products - it also offers initial evidence on how observers' values moderate the picture formed of a consumer who is believed to be an organic food user. In Study 3, instead of explicit measures of consumer images, more implicitly formed images are accessed. The image effects not only re-emerge, but are also accompanied by data indicating that organic food users are more favorably treated in social interactions. Finally, the conclusions, implications and limitations of the research are discussed.

\section{Justification of the organic food study context and development of research hypotheses}

For organic food consumption — or any behavioral strategy whatsoever — to qualify as a costly signal, four criteria need to be met (Nelissen \& Meijers, 2011). First, the signal must be easily observable. Second, the signal must be "honest" or hard to fake (because of high associated economic and social costs). Third, the signal must be associated with an unobservable, yet desirable, individual quality, such as wealth, altruism, or physical health - traits partly connected 
with good genes. Fourth, the signal must ultimately yield a fitness benefit. In evolutionary biology, the concept of fitness indicates the share of an individual's genes in the following generations - it is enhanced through improved reproduction and survival (Hamilton, 1964).

As organic foods are distinctly marketed (e.g., Van der Wal, van Horen, \& Grinstein, 2016), becoming mainstream worldwide (Shang \& Peloza, 2016), more expensive than conventional foods (Rana \& Paul, 2017) and possess unique brand equity (Ellison, Duff, Wang, \& White, 2016), they meet the first and second preconditions reasonably well. In this research, the way organic food users are perceived and treated serves as an indication of whether the last two criteria of a costly signal are fulfilled or not. Moreover, of the three most obvious forms of prosocial food consumption, the economic significance of organic food consumption is larger than that of fair trade products - in 2015, global retail sales of organic food amounted to 75.7 billion euro while the corresponding figure for fair trade food was 7.3 billion euro (Lernoud et al., 2015). Local foods, on the other hand, lack a clear definition and their marketing is subject to variable brand management actions both between and within countries (Memery, Angell, Megicks, \& Lindgreen, 2015). Thus, this ambiguity in signal meaning makes local food consumption a less appropriate target of the analysis for the present study.

\subsection{Interpretation process of cues signaling about favoring organic food}

Here, the overall psychological process that is postulated to underlie the interpretation of cues signaling about favoring organic food is conceptually elaborated. It draws from the continuum model of consumer impression formation (Fiske et al., 1999) and the symbolic consumption theory (see e.g. Elliott, 2013; Kim \& Jang, 2017). This theorizing is predicated on two premises. First, the generic concept of "organic" is taken to be a powerful brand and a vehicle of identity 
expression in its own right in the same way as single food product brands are (Bauer, Heinrich, \& Schäfer, 2013; Hwang, 2016). Second, during the process of impression formation, the traits of the "organic" brand personality are presumed to merge with the image of its user - which, in turn, serves as input in observing consumers' perceptual inference making (Fennis \& Pruyn, 2007).

The interpretation process commences by observing the signal transmission that, in the context of the present study, includes the cues suggesting the habitual use of organic foods. Consistent consumption of such foods serves as the starting point, as it marks the honesty of the signal. Receivers of this signal decode it in the service of image formation. It is well-known that personal food choices act as a vehicle of impression management (Vartanian et al., 2007; Bublitz, Peraccio, Block, 2010). In the consumer image formation process, both factual and symbolic cues related to the person (Brooks \& Wilson, 2015) and the product s/he uses (Allen et al., 2008) are elaborated more or less automatically and/or strategically (Sanders, 2010). Noppers, Keizer, Bolderdijk, and Steg's (2014) study on adoption of sustainable innovations provides a case-in point. They found that while consumers readily recognize the importance of instrumental benefits (e.g., "comfortable," "affordable"), the symbolic benefits (e.g., "shows who I am," "enhances my social status") were in fact the strongest predictors of adoption even though consumers denied their significance when directly asked at the conscious level.

At the final stages of the process, signal receivers consciously (deliberate use of attribute information), nonconsciously (automatic use of category labels) or through using both processing modes generate an interpretation of the meaning of the signal (Fennis \& Pruyn, 2007; Sanders, 2010). Thereby, the signal receiver forms an image of the signal sender and becomes inclined to treat him/her in a certain way in social encounters. Intriguingly, sometimes the explicit and 
implicit beliefs concerning the same object can be contradictory and even produce different behavioral consequences (see e.g., Raghunathan, Walker-Naylor, \& Hoyer, 2006).

\subsection{Hypothesis 1: Do organic food users create a prosocial status-signaling image?}

Which image perceptions, evoked in observers' minds by the organic food choices of fellow consumers, would be consistent with the idea of prosocial status signaling? This is a critical question that the first hypothesis addresses - identifying three such characteristics.

First, as classically defined, status-signaling refers to a tendency to purchase and display branded goods and services without an obvious functional utility (cf. luxury) for the social prestige value they confer on their owners (Han et al., 2010). To illustrate, Lee et al. (2015), when considering apparel brands as costly signals, found that those consumers wearing more luxurious shirts (Louis Vuitton) were viewed as wealthier and more respected than their identical counterparts in less luxurious shirts $(\mathrm{H} \& \mathrm{M})$. The higher price - both actual and perceived - of

organic foods (Bryla, 2016; Rana \& Paul, 2017), coupled with their potential "sustainable luxury" aura (Cervellon \& Shammas, 2013) makes them consistent with these status-signaling aspects. Moreover, high status has been associated with prosociality and pro-environmentalism (De Nardo, Brooks, Klinsky, \& Wilson, 2017). Thus, image qualities akin to prestige should logically resonate with favoring organic food as a form of prosocial status signaling.

Second, as the adjective "prosocial" indicates, an element of altruism should permeate the image perception of a consumer exercising prosocial status signaling. In their pre-test, Griskevicius et al. (2010) confirmed that owners of green products were perceived to be nicer, more caring and altruistic than the owners of equivalent non-green products. In a similar vein, 
consumers purchasing organic foods and environmentally friendly products were viewed as more co-operative, altruistic and ethical than consumers who purchased conventional foods and products (Mazar \& Zhong, 2010). According to Antonetti and Maklan (2016), users of responsible brands (e.g., Tom's of Maine) were perceived as more friendly, good-natured, tolerant and warm than users of less responsible brands (e.g., Tide). In other words, the image attributes with altruistic connotations should characterize consumer choices qualifying as prosocial status signals - favoring organic food is one ample manifestation of such choices.

Third, the perception of honesty can be expected to impregnate the image of consumers engaging in prosocial status signaling. Indeed, Fehrler and Przepiorka (2013) discovered that truly altruistic acts serve as costly signals that make those who perform them seem more trustworthy interaction partners in social exchange. Consumers perceive products of truly (vs. superficially) prosocial companies to perform better (Chernev \& Blair, 2015) and socially penalize those who brag about their good deeds for others - transforming an inherently virtuous behavior into an act of phony selfishness (Berman et al., 2015). The honesty perceptions evoked by organic food users have not yet received scholarly attention. However, a comparable study by Neel, Sadalla, Berlin, Ledlow, and Neufield (2014) showed that consumers who preferred more vegetation in their yard landscaping were viewed as more conscientious, akin to honesty. This hints that the honesty image associations are likely to be a part of prosocial status signaling occurring through green consumption such as organic food use.

In conclusion, three key image qualities, vital for a prosocial status signal, have been identified. Moreover, favoring organic food has been conceptually linked to them. Consequently, the first hypothesis can be stated as follows: "Those consumers who signal about their habit of favoring organic foods are perceived as more altruistic, status-laden and honest than consumers 
who do not." This hypothesis will be tested in Studies 1 and 2.

\subsection{Hypothesis 2: Role of observers' self-transcendent and conservative values in formation of} the image of an organic food user

The formation of the image of an organic food user is naturally moderated by many factors (Fiske et al., 1999). Here, the focus will be on the observer characteristics affecting the interpretation of the reputational signals emitted by the choices of their fellow consumers. Saher, Arvola, Lindeman, and Lähteenmäki (2004) showed how observers' gender and age affected their perceptions of consumers favoring conventional vs. functional foods. In food consumption, values have been afforded a significant role in shaping and influencing a wide range of responses such as product perceptions (e.g. Botonaki \& Mattas, 2010), brand evaluations (e.g. Laureati, Jabes, Russo, \& Pagliarini, 2013), choices (e.g. Fotopoulos, Krystallis, \& Pagiaslis, 2011) and even sensory experiences (e.g. Paasovaara, Luomala, Pohjanheimo, \& Sandell, 2012). Thus, there are good reasons to theorize about their potential to moderate observers' perceptions of organic food users.

Willer (2009) conjectured that the image of a person engaging in prosocial behaviors is dependent on the extent to which the group noting this appreciates altruism in general. In fact, Sexton and Sexton (2014) found that driving a Toyota Prius hybrid car confers a greater benefit in communities with strong environmental values. In a similar vein, Brooks and Wilson (2015) proposed that observers' environmental orientation (cf. values) affect the perceived status of a person believed to purposively reduce consumption. 
As suggested in the Introduction, organic food choice motivations reveal that it can symbolize wellbeing, hedonism, universalism, security, ethicality and status for consumers. Symbolic product meanings form a tight relationship with consumers' values as their congruence or incongruence can influence many responses from choices to taste sensations (Allen, Gupta, \& Monnier, 2008; Paasovaara et al., 2012). One influential approach to consumer values includes Schwartz's 10-class typology which can also be presented with the help of four more abstract meta-categories: openness to change (stimulation, self-direction, hedonism); self-transcendence (universalism, benevolence); conservation (security, tradition, conformity); and selfenhancement (achievement, power) (Caracciola et al., 2016). In line with the consumer value/product symbolism (in)congruity referred to above, a positive moderation can be expected when observers' values are congruent with the key symbolic meanings they attach to organic foods and eventually to people who consume them.

On the basis of past literature, the meta-values of self-transcendence (universalism, benevolence) and conservation (security, tradition, conformity) are most likely to be congruent with organic food associations. Universalism has been found to be the dominant value guiding consumers' purchase of organic food (Dreezens, Martijn, Tenbült, Kok, \& De Vries, 2005; Thogersen, Zhou, \& Huang, 2016). Typically, in organic food consumption studies, the role of the benevolence value has not been isolated from that of universalism (e.g., Lea \& Worsley, 2005; Krystallis, Vassallo, Chryssohoidis, \& Perrea, 2008). Yet, it has been reported that a high frequency of organic food consumption is related to the benevolent value of "spiritual life" (Kihlberg \& Risvik, 2007) and that concern for animal- and environment-friendly (cf. organic) meat production is correlated with it (de Boer, Hoogland, \& Boersema, 2007).

Of the values making up the conservation meta-category, the security value belongs, 
according to the extensive review of Aertsens Verbeke, Mondelaers, \& Huylenbroeck (2009), among the strongest organic food consumption motivations. Second, the results of Vermeir and Verbeke (2008) show that consumers who hold traditional values (e.g., being humble and devout, respecting traditions, holding no extreme ideas or feelings) are more inclined to buy sustainable foods such as organic dairy products. Finally, the conformity value influences the "subjective norm" via the motivation to go along with the expectations of others (Aertsens et al., 2009). In the context of organic food consumption, Dean, Raats, and Shepherd (2008) find a significant positive relation between consumers' intention to purchase organic food and their desire to conform with other people.

In summary, consumers' personal values steer which food choice motivations are most influential (Pohjanheimo, Paasovaara, Luomala, \& Sandell, 2010). In turn, as stated in Introduction, choice motivations reflect the symbolic contents consumers attach to food. Organic foods embody several meanings. Importantly, these meanings may be more or less automatically transferred to organic food users by observing consumers (Sexton \& Sexton, 2014; Vartanian, 2015). Yet, observers' own values guide what meanings they will most readily associate with organic foods and, therefore, their users. Observers with self-transcendent values are likely to see organic food users generally in the positive light because the former regard the latter as friendly to environment and animals. Conservative observing consumers may do the same, but for different reasons: organic food users can be viewed favorably due to their apparent efforts to foster safety and wellbeing of society. More formally, the congruity between observers' values and the qualities attributed to organic food users (observer self-transcendence $\rightarrow$ organic food user as a promoter of environmental friendliness and animal welfare; observer conservatism $\rightarrow$ organic food user as a promoter of societal safety and wellbeing) is proposed to heighten the 
overall perception of a person.

Consequently, it can be hypothesized that: “Observing consumers' self-transcendent and conservative values positively moderate the extent to which organic food users are viewed as altruistic, status-laden and honest.” This second hypothesis will be tested in Study 2.

\subsection{Hypothesis 3: Are organic food users nonconsciously viewed and treated more positively?}

Especially the first impressions of food products are often created through less conscious processing of a few salient and sometimes even trivial cues (Puska \& Luomala, 2016). The same applies when the first impressions of other consumers are formed (Chan, Berger, \& van Boven, 2012). As explained earlier, the continuum model of impression formation acknowledges that in certain conditions images of other consumers are automatically constructed based on nonconscious quick-snap instant categorizations (Fennis \& Pruyn, 2007). A vast body of research suggests that individuals rapidly make inferences and judgments about others' competence and status as a result of observable signals, such as appearance, verbal and nonverbal behaviors, attitudes, and consumer choices (Bellezza, Gino, \& Keinan, 2014).

No conceptual rationale has as yet been provided for the claim that favoring organic food as a prosocial status signal can yield a fitness benefit for the sender. As actual fitness benefits deriving from single status consumption acts are virtually impossible to demonstrate in a singleshot study, a conceptual proxy is needed to represent them (cf. Nelissen \& Meijers, 2011). One logical solution to this is to assess how benevolently observing consumers behave toward the prosocial status signal sender. According to Kafashan, Sparks, Griskevicius, and Barclay (2014), prosocial people tend to receive social benefits from others; for example, they were entrusted with a larger sum of money and more preferred as interaction partners and leaders. In a study on 
religious costly signaling, Soler (2012) discovered that individuals who reported higher levels of religious commitment behaved more generously in a public goods game and detailed more instances of cooperation provided and received within their community.

In the consumption context, studies involving an analysis of how costly signalers are socially treated by observers have been rarely conducted. Both of them deal with luxury brand consumption as costly signaling. However, the applicability of their results in the case of prosocial status signaling cannot be challenged outright. Nelissen and Meijers (2011) showed that conspicuous displays of prestigious clothing brands can be a profitable affiliative strategy because they qualify as a costly signaling trait that yield status-dependent favorable treatment from others in social interactions such as complying with a request, determining wage levels for job applicants and donating money to charity. Lee et al. (2015) practically replicated this study in a different cultural context - with similar findings. Yet, they considered the role of gender in more detail and demonstrated that cross-sex contexts are more effective in eliciting donation behaviors from observing consumers (Lee et al., 2015).

Based on the discussion above, an unprecedented idea can be put forth: Just as luxury brand consumption can serve a costly signaling function leading to benevolent behaviors from others toward the signaler or message sender, so too can favoring organic foods. Here, it is more appropriate to name this status signaling as prosocial, since it is more altruistically driven than traditional luxury consumption (Griskevicius et al., 2010). In effect, both of these consumption choices (luxury brands vs. organic foods) have the capability to qualify as costly signals in the eyes of observers and encourage favorable treatment from them. Still, these choices elicit respect in different ways due to variation in observers' evaluation of who mainly benefits from this use of excessive resources (self vs. others). 
The relationship between signaling about one's habit of favoring organic foods and the social treatment received from others observing this is likely to be mediated by the changes in the image perceptions of the signaler. Lee et al. (2015, p. 1348) state that the higher perceived status of the wearer of a luxury brand produces benefits in social interactions, and Nelissen and Meijers (2011, Experiment 5) actually empirically verify how the signaling effect on preferential treatment materialized through elevated status perceptions. In a similar vein, Brough, Wilkie, Ma, Isaac, and Gal (2016, Study 6A) found that increased masculinity perceptions (created by branding) of a green nonprofit organization were responsible for boosting male consumers' donation likelihood.

To summarize, observing someone using organic foods can act as subtle input in forming a nonconscious image of him/her in the same way as meat eaters are implicitly viewed as more masculine (Vartanian, 2015). Second, as organic food users are associated with prosocial tendencies, they can also receive preferential treatment from others. For instance, priming a consumer's prosociality orientation has been found to increase the amount of money personally given to a fellow consumer in a dictator game (Duclos \& Barasch, 2014). Third, it is logical to assume that enhanced image perceptions mediate the effect of prosocial status signaling. Consequently, the third hypothesis can be stated as follows: "Those consumers who signal about their habit of favoring organic foods are nonconsciously perceived as more altruistic, statusladen and honest as well as, consequently, more positively treated in social interactions than consumers who do not." This hypothesis will be tested in Study 3.

\section{Study 1: Test of hypothesis 1}

Study 1 sought initial empirical evidence for the postulate that consumers who favor organic 
foods are viewed as more altruistic, status-laden and honest (hallmarks of a prosocial status signal). To this end, a convenience sampling approach was applied and local food markets were scouted for products available in both conventional and organic forms. Eventually, ketchup, bacon and coffee were selected for the study. Their conventional and organic versions were practically the same except the organic label on the package (see Appendix 1).

These foods were selected to ascertain two things. On the one hand, the requirement for a reasonable level of generalizability necessitated the incorporation of items from distinct product categories. Namely, consumers favor organic options across various product classes (e.g., meat vs. vegetables) to a different extent (Hemmerling, Hamm, \& Spiller, 2015). Moreover, the effects of the organic cue have been shown to differ between individual food products (Ellison et al., 2016). On the other hand, a certain degree of between-product comparability was also desirable to enhance the reliability of the results. Thus, the products chosen for the survey were controlled for their level of processing as according to Machiels and Carnal (2016) it can have a role in how foods are perceived. This suggests that users of minimally vs. highly processed (organic) foods can be viewed differently. Ketchup, bacon and coffee were construed to represent moderately processed products.

\subsection{Study design and sample}

A political science student association of a university located in a European capital consented to forward the website-link to the survey to its 2,140 members. No incentives were promised for participation - this also served to guarantee full anonymity as no personal contact information was needed. One hundred eighty-seven $(\mathrm{N}=187)$ usable responses were retained - a response rate of $8.7 \%$. The majority ( $83 \%$ ) of the study participants was females. This is not surprising as 
roughly $80 \%$ of political science students at the university where the data collection occurred are female. On the average, the participants were 26.2 years old.

A six-group between-participants design was applied (for details, see Appendix 2). Each participant was randomly assigned to one of the conditions where the consumer being evaluated was presented as a regular user of 1) conventional ketchup $(\mathrm{N}=28), 2)$ organic ketchup $(\mathrm{N}=$ 36), 3) conventional bacon $(\mathrm{N}=32), 4)$ organic bacon $(\mathrm{N}=44), 5)$ conventional coffee $(\mathrm{N}=21)$, and 6) organic coffee $(\mathrm{N}=27)$.

\subsection{Study procedure and questionnaire}

The student participants received an e-mail requesting them to participate in an academic consumer impression study. The first questions concerned their gender and age. The second section of the questionnaire, entitled "Images created by consumers favoring various food products," dealt with the measurement of the key dependent variable. The photo of the food product was shown and participants were asked to indicate how they perceived its regular user (an example question: "In my opinion, the regular user of organic Felix ketchup can be characterized as...). In the case of the conventional product questions, no words such as "organic" or "conventional" were mentioned. This questioning logic - also referred to as the "user imagery" approach - has a long tradition in consumer research; it has been applied to uncover product and brand images (Parker, 2009) and their effects on consumer perceptions and attitudes (Liu, Li, Mizerski, \& Soh, 2012). Here, this approach was harnessed to track the images typical users of organic and conventional foods evoke in the minds of others. To conceal the real purpose of the research, photos of three filler-products (see Appendix 2) were also shown to participants alongside identical image questions. 
As this was the first trial to examine if the image transmitted by organic food users matches the characteristics of a prosocial status signal, single-item measures were applied to capture the perceived consumer image. The 9-point semantic differential "unselfish-selfish" served as the measure of altruism - it has been used to tap the prosociality image of green consumers (Griskevicius et al., 2010). Along the lines of Fennis and Pruyn (2007), Aaker's (1997) sophistication and sincerity dimensions of brand personality served as the measures of observers' status and honesty perceptions of the image conveyed by other consumers. Sophistication refers to cultivation and expertness concerning food, drink, clothes and furnishings used to signal class status (Gofman, 1951). It has also been linked to status and social prestige in more current literature. For example, Eckhardt, Belk, and Wilson (2015) argue that the rise of inconspicuous consumption emanates from "an increased desire for sophistication and subtlety in design in order to further distinguish oneself from a narrow group of peers" and that "sophistication in design implies meticulous engineering and an intricacy that elevates the status of the designer and, by extension, the consumer.” In turn, qualities such as down-to-earth, honest, wholesome, genuine and domestic transmit a sincere image (Aaker, 1997). Consequently, the 9-point semantic differentials "unsophisticated-sophisticated" and "fake-sincere" gauged the status and honesty-perceptions of consumers presented as favoring either conventional or organic versions of ketchup, bacon and coffee. Finally, a few control questions (e.g. product familiarity and brand attitudes) were posed.

\subsection{Results and discussion}

One-way ANOVA was conducted to estimate if the food user manipulation (conventional vs. organic) differed in its effect on the consumer image measures (see Table 1). In comparison with 
the regular user of conventional ketchup, a consumer believed to favor organic ketchup was perceived as more altruistic $(F(1,61)=16.31, p<.001, d=1.45)$ and status-laden $(F(1,61)=$ $16.70, p<.001, d=1.03)$. Second, a consumer believed to favor organic bacon was perceived as more altruistic $(F(1,74)=17.93, p<.001, d=1.08)$ and status-laden $(F(1,74)=8.89, p=.004$, $d=0.71$ ). Third, a consumer believed to favor organic coffee was perceived as more altruistic $(F(1,46)=5.02, p=.03, d=0.77)$ and status-laden $(F(1,46)=10.06, p=.01, d=0.94)$. As regards the honesty-image perception, no differences between the conditions were detected $\left(F_{\text {ketchup }}(1,61)=0.45, p=.50, d=0.18 ; F_{\text {bacon }}(1,74)=1.35, p=.25, d=0.27 ; F_{\text {coffee }}(1,46)=\right.$ $0.01, p=.91, \mathrm{~d}=0.03)$.

\section{Table I.}

The effect of favoring conventional vs. organic food on forming consumer image

\begin{tabular}{|c|c|c|c|c|c|c|c|c|c|c|c|}
\hline \multirow{3}{*}{ Image dimension } & \multicolumn{3}{|c|}{ Ketchup } & \multicolumn{4}{|c|}{ Bacon } & \multicolumn{4}{|c|}{ Coffee } \\
\hline & \multicolumn{2}{|c|}{$\begin{array}{c}\text { Favors }(\mathrm{N}=28) \\
\text { conventional }\end{array}$} & $\begin{array}{c}\text { Favors } \\
(\mathrm{N}=36) \text { organic }\end{array}$ & \multicolumn{2}{|c|}{$\begin{array}{c}\text { Favors }(\mathrm{N}=32) \\
\text { conventional }\end{array}$} & \multicolumn{2}{|c|}{$\begin{array}{c}\text { Favors } \\
(\mathrm{N}=44) \text { organic }\end{array}$} & \multicolumn{2}{|c|}{$\begin{array}{c}\text { Favors }(\mathrm{N}=21) \\
\text { conventional }\end{array}$} & \multicolumn{2}{|c|}{$\begin{array}{c}\text { Favors } \\
(\mathrm{N}=27) \text { organic }\end{array}$} \\
\hline & & S.D. & Mean S.D. & & S.D. & Mean & S.D. & & S.D. & Mean & S.D. \\
\hline Altruism & $4.79^{a}$ & 0.78 & $6.22^{b}$ & $3.75^{\mathrm{a}}$ & 0.92 & $4.93^{\mathrm{b}}$ & 1.25 & $5.48^{\mathrm{a}}$ & 1.00 & $6.26^{\mathrm{b}}$ & 1.02 \\
\hline Status & $3.32^{\mathrm{a}}$ & 1.61 & $5.00^{b}$ & $3.28^{\mathrm{a}}$ & 1.14 & $4.25^{\mathrm{b}}$ & 1.56 & $3.00^{\mathrm{a}}$ & 1.10 & $4.22^{\mathrm{b}}$ & 1.48 \\
\hline Honesty & $5.57^{\mathrm{a}}$ & 1.34 & $5.33^{\mathrm{a}}$ & $5.34^{\mathrm{a}}$ & 1.23 & $4.98^{\mathrm{a}}$ & 1.44 & $6.00^{\mathrm{a}}$ & 1.05 & $6.04^{\mathrm{a}}$ & 1.26 \\
\hline
\end{tabular}

To check if these results are dependent on the specific food products included in the study, a 2 (food label: organic vs. conventional) x 3 (food type: ketchup vs. bacon vs. coffee) ANOVA was conducted. As all of the interaction terms were statistically insignificant (altruism: $F(2,181)$ $=0.83, p=.44$; status: $F(2,181)=1.07, p=.35$; honesty: $F(2,181)=0.53, p=.70)$, it can be concluded that the results were not driven by the inherent properties of individual products. Finally, the perceptual results cannot be explained by the differences in participants' age, income, familiarity with the conventional and organic versions of the products or brand attitudes - $p$ s ranged from .17 to .99 from the one-way ANCOVA analysis using the perceptions as DV, 
presence of organic food label (yes vs. no) as an independent variable (IV) and the abovementioned factors as covariates. Moreover, none of the statistically significant key effects reported above turned insignificant in this ANCOVA analysis indicating that the presence vs. absence of the organic food label (IV) logically explains the changes in the user perceptions. The role of gender could not be controlled for due to the low number of male participants.

In summary, across three products, the image of organic food users was characterized by a higher degree of altruism and status. These image effects are congruent with the prosocial status signaling interpretation. On the other hand, statistically significant findings for honesty could not be uncovered - casting some doubt on this idea. Nevertheless, these results complement current understanding in two ways. First, until now, scholars have focused their attention on how green consumers are viewed by others in terms of altruism - typically with positive effects

(Griskevicius et al., 2010; Mazar \& Zhong, 2010). The current findings imply that green consumers may be perceived not only as more altruistic, but also as more status-laden than their non-green counterparts. Second, they suggest that consumer perishables such as organic foods have the capability to act in the service of prosocial reputation management. This challenges the prevailing idea that symbolic attributes - thought to be less suitable for signaling one's status or identity to others - would not be important in mundane sustainable consumption (Noppers et al., 2014).

\section{Study 2: Test of hypotheses 1 and 2}

Study 1 initially demonstrated that organic food choices can act as prosocial status signaling. Yet, the results were based on a student sample in which women were overrepresented. This raises some validity concerns as women favor organic foods more than men (Padilla Bravo, 
Cordts, Schulze, \& Spiller, 2013). Thus, Study 2 strove to test their robustness with a more representative sample and a wider range of products. The second aim was to explore if signal observers' values influence the image formed of organic food users.

\subsection{Study design, procedure, questionnaire and sample}

The study design, procedure and questionnaire were identical to that of Study 1, with two exceptions: 1) another three commercial products available in both conventional and organic versions (yogurt, butter, canola oil) and 2) a short measure of Schwartz's ten value classes, SSVS, (Lindeman \& Verkasalo, 2005) were added. As in Study 1, data was collected from six participant groups (for details, see Appendix 2). This time, however, one more product was included in each of the questionnaires to further safeguard against the potential confounder effect arising from the specific nature of the individual products being investigated. In other words, each participant was randomly assigned to one of the conditions where the consumer being evaluated was presented as a regular user of 1) conventional ketchup and conventional butter (N $=43), 2)$ organic ketchup and organic butter $(\mathrm{N}=40), 3)$ conventional bacon and conventional yogurt $(\mathrm{N}=44), 4)$ organic bacon and organic yogurt $(\mathrm{N}=44), 5)$ conventional coffee and conventional canola oil $(\mathrm{N}=44)$, and 6$)$ organic coffee and organic canola oil $(\mathrm{N}=44)$. (For the justification of this approach, see Section 3.2.) As in Study 1, to conceal the real purpose of the research, the photos of the same three filler products were also shown to participants alongside the identical image questions. To enhance the comparability of the results between Studies 1 and 2 and in the fear of response fatigue, single-item measurements were retained. The addition of new products whose regular users were evaluated increased the number of necessary image ratings and questions about product familiarity and brand attitude. Lastly, the new SVSS-items 
contributed to the fact that the questionnaire approached or even reached 20 minutes - nearing the maximum length of optimal web surveys (e.g., Kent, 2007, p. 166).

A sample $\left(\mathrm{N}_{\text {total }}=259, \mathrm{~N}_{\text {conventional user cue }}=131, \mathrm{~N}_{\text {organic user cue }}=128\right)$ that is more representative of "ordinary" consumers living in the same capital region as the participants of Study 1 was provided by a market research firm, committed to protecting the full anonymity of its panel members. The sample consisted of $51 \%$ females. On the average, participants were 48.8 years old and the majority of them (58\%) lived in children-free households of one or two person(s). The typical yearly household income levels were: 40,000-69,999 € (26\%), 20,000$39,999 €(20 \%)$ and 70,000-89,999€(17\%).

\subsection{Results and discussion}

An alternative analytical approach was undertaken to explore if the main effects discovered in Study 1 would reappear. One single composite measure for each consumer image dimension was produced to level out the potentially idiosyncratic effects of individual products. To illustrate, the sum variable for the status image of a consumer who was believed to regularly use conventional foods was created by combining the image ratings collected separately for all of the six conventional products. Thus, instead of referring to the status image conveyed by a user of conventional ketchup, butter, bacon, yogurt, coffee or canola oil, it is more appropriate here to allude to the status image that a consumer regularly using conventional foods more generally evokes in the minds of observing others. This same procedure was followed in generating the aggregate honesty- and altruism-image dimension scores. In other words, six composite consumer image measures served as input data in the analysis: 1) the altruism image cued by the use of conventional foods, 2) the altruism image cued by the use of organic foods, 3) the status 
image cued by the use of conventional foods, 4) the status image cued by the use of organic foods, 5) the honesty image cued by the use of conventional foods and 6) the honesty image cued by the use of organic foods.

One-way ANOVA produced the following results. The strongest effects were recorded for altruism $\left(M_{\text {conventional user }}=5.26\right.$, S.D. $=1.15 ; M_{\text {organic user }}=5.75$, S.D. $=1.40 ; F(1,257)=9.49, p=$ $.002, d=0.38)$ and status $\left(M_{\text {conventional user }}=4.79\right.$, S.D. $=1.36 ; M_{\text {organic } u s e r}=5.63$, S.D. $=1.10 ; F(1$, $257)=29.75, p<.001, d=0.68)$. A marginal effect was observed for honesty $\left(M_{\text {conventional user }}=\right.$ 5.70, S.D. $=1.26 ; M_{\text {organic user }}=6.00$, S.D. $\left.=1.33 ; F(1,257)=3.42, p=.07, d=0.23\right)$. As in Study 1, an additional analysis was run to inspect if these results are shaped by inherent product characteristics of the foods incorporated into the study. The 2 (food label: organic vs. conventional) x 3 (food type: ketchup and butter vs. bacon and yogurt vs. coffee and canola oil) ANOVA produced two statistically insignificant indications of interaction and one marginally significant indication (altruism: $F(2,253)=0.18, p=.83$; status: $F(2,253)=2.90, p=.06$; honesty: $F(2,253)=2.20, p=.11)$. This, again, speaks for the cross-product generalizability of the prosocial status signaling effect. Moreover, these perceptual results cannot be explained by the differences in participants' gender, age, income level, familiarity with the conventional and organic versions of the products or brand attitudes ( $p$ s ranged from .13 to .70). The influence of these factors, excluding gender, were ruled out after running the ANCOVA analysis comparable to those reported in Study 1 (see Section 3.3.). In turn, the potentially confounding role of gender, as a nominal variable, was controlled with the help of 2 (respondent gender: male vs. female) x 2 (organic food label: yes vs. no) ANOVA. As regards the perceptions (DVs), it produced statistically insignificant interaction terms: altruism: $F(2,255)=0.71, p=.40$; status: $F(2,255)=0.00, p=.99$; honesty: $F(2,255)=0.18, p=.68$. Again, as in Study 1 , these analyses 
did not alter the statistical significance of the perceptual effects reported above. Hence, it is the presence vs. absence of the organic food label (IV) that appears to drive the results.

In a nutshell, despite the more representative sample, extended range of products and alternative analytical approach, the results of Study 1 are practically replicated. Unobservable desirable characteristics such as altruism, status and honesty, akin to a prosocial status signal, were attached to the consumers believed to favor organic foods.

Next, the attention shifted toward the potential moderating effect of observers' values on how a (non)user of organic food is perceived. To scrutinize this aspect of $\mathrm{H} 2$, two value classes were formed along the meta-dimensions of Schwartz's value circumplex model (see, e.g., Caracciolo et al., 2016): self-transcendence value (universalism, benevolence; $\alpha=.700$ ) and conservatism value (tradition, conformity, security; $\alpha=.788$ ). Then, the interaction effects of the IVs (value: self-transcendence vs. conservatism; food user cue: conventional vs. organic) on the altruism, status and honesty perceptions were inspected by conducting Hayes's (2017) PROCESS macro (model 1, with 5,000 resamples). The analysis involving self-transcendence values did not discern statistically significant interaction terms $(p s>.25)$. However, as regards the altruism perception, the results showed proof for conservative value moderation $(\beta=.29$, $t(255)=2.19, p=.03 ; \mathrm{CI}=.03$ to .54$)$. This moderation was not detected for the status and honesty perceptions $(p s>.27)$.

Consequently, this interaction was considered in more detail. The disentanglement of the specific conditional effects revealed that when the conservatism value exhibits medium or high scores, an organic food user (as opposed to a conventional food user) was viewed as more altruistic $(\beta=.44, t(255)=2.88, p=.04 ; \mathrm{CI}=.14$ to $.74 ; \beta=.78, t(255)=3.60, p=.004 ; \mathrm{CI}=$ .35 to 1.21 , respectively). At the low level of conservatism, this difference no longer persists ( $\beta=$ 
$.10, t(255)=.47, p=.64 ; \mathrm{CI}=-.33$ to .54$).$ Stated differently, as the importance of conservative values grows, the perception of an organic food user as being altruistic intensifies. Figure 1 illustrates these findings.

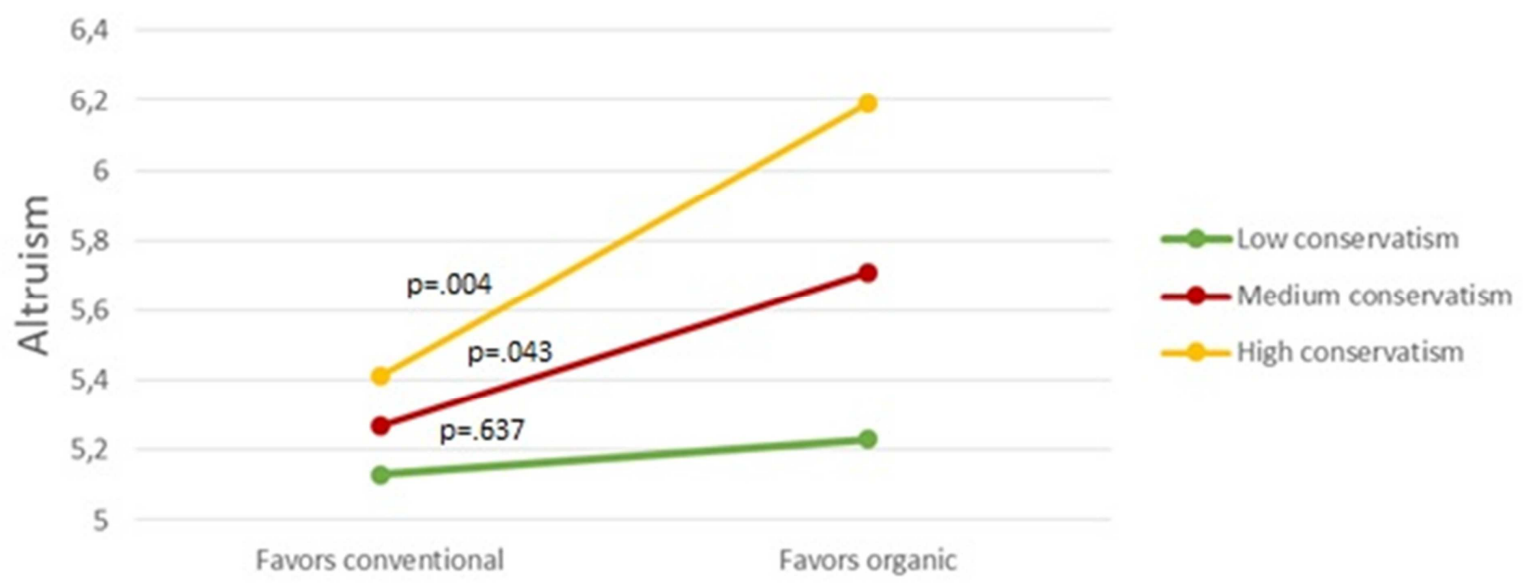

Figure 1.

Moderating effect of the conservatism value on altruism perception of an organic vs. conventional food user

In summary, unprecedented empirical evidence for the ability of observing consumers' values to moderate the image formed of (non)users of organic foods could be gleaned: observers with stronger conservative values perceived organic food users as more altruistic. Thus, observers' personal characteristics such as values can influence the extent to which an organic food user is perceived as a prosocial status signaler. The interpretation of this result is elaborated in Discussion.

\section{Study 3: Test of hypothesis 3}

In Studies 1 and 2, the image of a (non)user of organic foods was most likely formed more explicitly and consciously due to their methodological approach. Thus, it was deemed important to address whether similar image effects are also created less consciously. Second, are 
consumers signaling about their habit of using organic foods also more favorably treated (potential generation of fitness benefit) by others observing this? These important pieces of evidence were sought in Study 3.

\subsection{Study design, sample and manipulation material pre-test}

A two-group between-subjects study design was used. The data collection occurred in the same European capital. Study participants were recruited from a mall - full anonymity was promised and no data relevant for identifying them later was collected. They were intercepted and those who agreed to take part were asked to carefully look at a picture showing a person preparing a green salad for $30-60$ seconds, after which they responded to the key study questions (i.e., dependent and control measures) - see Section 5.2. Preparation of a green salad was chosen as the focal form of food consumption to be portrayed in the picture as most people can relate to it easily; for example, only $30 \%$ of American young adults never do it (Nelson Laska, Larson, Neumark-Szteiner, \& Story, 2012); and the ingredients for a green salad are readily available in both conventional and organic varieties. The survey took 3-6 minutes to complete. The sample consisted of 336 shoppers $\left(\mathrm{M}_{\mathrm{age}}=28 ; 51 \%\right.$ females; $46 \%$ possessed a university degree $)$.

In half of the questionnaires, the depicted person wore a blank white t-shirt and in another half a white t-shirt with a nationally used organic logo on it (see Appendix 1). This ladybug logo was preferred to the official EU organic logo, as it is almost equally known among local consumers and includes a direct reference to organic production (the version with the word "organic" in the local language was used - see Appendix 1). It was thought to boost the logo's attention value and decrease the risk of miscomprehension - which turned out to be true (see the results of the pre-test below). This manipulation method (t-shirts with vs. without logos) has 
been utilized and validated in previous studies (Nelissen \& Meijers, 2011; Lee et al., 2015). The assignment of participants to either of these groups occurred randomly. In line with wellestablished approaches to discovering implicit effects (e.g., Brasel \& Gips, 2011; Park \& Roedder John, 2014), the logo acted as a subtle cue suggestive of a user of organic foods.

A separate pre-test $(\mathrm{N}=60)$ was conducted in the same setting to ensure that the organic logo would be noticed and understood as intended. After a background information check, pretest study participants were first instructed to look at the picture (version with the logo) and then to answer certain control questions (at this stage they no longer saw the picture) relating to the person in the picture (e.g., color of his/her hair and T-shirt, chopped vegetable). Next, they were asked to indicate if they noticed a logo in it (logo options: fair trade, local food, Adidas, Tommy Hilfiger, a domestic dairy brand and the ladybug) and, if they did, what kind of products they think it represents (again six options: locally produced foods, fair trade products, organically produced foods, domestic dairy products, sport products and luxury products). The results were unequivocal: 93\% remembered seeing the ladybug logo and, more importantly, all of them understood that it refers to organically produced foods. To conclude, the manipulation instrument used (the ladybug logo with the text organic on a white T-shirt) elicited the expected outcome.

\subsection{Study procedure and questionnaire}

As in Studies 1 and 2, participants were asked to take part in a study dealing with consumer impressions. No incentives were offered for participation. The questionnaires were filled in on a portable plastic clipboard. The queries concerning gender, age, place of residence as well as household size and income were presented first. Next, a picture of a male or female making a green salad in an ordinary kitchen was displayed - s/he wore either an organic-labeled or a non- 
labeled white t-shirt. Quota sampling guided the data collection. Eighty-four responses were retained for each version of the questionnaire: 1) male salad-maker wearing a blank t-shirt $(\mathrm{N}=$ 84), 2) male salad-maker wearing an organic-labeled t-shirt $(\mathrm{N}=84), 3)$ female salad-maker wearing a blank t-shirt $(\mathrm{N}=84)$, and 4) female salad-maker wearing an organic-labeled t-shirt $(\mathrm{N}$ = 84). When approaching a potential participant, the field workers did not know which version of the questionnaire they would present.

To further cross-validate the image effects found in Studies 1 and 2, an alternative (multiitem) measuring battery (7-point Likert-scale) from Nelissen and Meijers (2011) was adapted: status ("this person has high status," "this person is respected"), honesty ("this person is trustworthy," "this person is honest") and altruism ("this person is unselfish," "this person is generous," "this person is helpful"). To reiterate, these impressions are critically relevant for prosocial status signaling. Six filler items (e.g., "this person is good-looking") were included to eliminate the priming effects on the following question asking how much money participants would give to the person in the picture if s/he were collecting donations for the disaster relief work of the local Red Cross. This question tracked how (un)favorably a consumer signaling about his/her habit of using organic foods is treated in social interactions. It is not a perfect measure of preferential social treatment, as it could tackle observers' willingness to donate more to the Red Cross when the collector favors organic foods, rather than address observers' more positive behaviors toward the person (raising the funds) per se. However, it has been used for this purpose in real-life field experiments (Nelissen \& Meijers, 2011; Lee et al., 2015) that delimit the use of more direct indicators of preferential social treatment such as dictator games. Lastly, participants' perceptions concerning the price level of organic foods in comparison to 
conventional ones across six product categories were tapped. Study participants were thanked and debriefed before they left.

\subsection{Results and discussion}

First, the reliability of the consumer image measurements was confirmed: status $(\alpha=.671)$, honesty $(\alpha=.750)$ and altruism ( $\alpha=.707)$. Second, an analysis was conducted to see if the image perceptions depend on the gender of the person in the picture - if not, then two larger groups (organic label on the t-shirt vs. no organic label on the t-shirt) could be formed. A 2 (gender of person in picture: male vs. female) x 2 (organic logo present on t-shirt: yes vs. no) ANOVA did not reveal any interactive effects on the image perceptions (altruism: $F(2,332)=0.05, p=.82$; status: $F(2,332)=1.55, p=.21$; honesty: $F(2,332)=0.04, p=.84)$. These results justified the use of two larger data sets, where the salad-makers in the picture consisted equally of men and women, in the analysis.

Next, one-way ANOVA produced results that to a reasonable extent converge with what Studies 1 and 2 discovered (see Table 2). The consumers believed to be users of organic foods received higher status, altruism and honesty ratings than the consumers believed to be non-users $\left(M_{\text {non-user }}=4.51\right.$, S.D. $=1.22 ; M_{\text {user }}=4.79$, S.D. $=0.92 ; F(1,344)=5.80, p=.02, d=0.26 ; M_{\text {non- }}$ $u_{\text {user }}=4.31$, S.D. $=0.89 ; M_{\text {user }}=4.56$, S.D. $=0.87 ; F(1,344)=6.65, p=.01, d=0.28 ; M_{\text {non-user }}=$ 4.83, S.D. $=1.02 ; M_{\text {user }}=5.06$, S.D. $=0.92 ; F(1,344)=4.73, p=.03, d=0.24$, respectively $)$. The only difference in the results pertains to the honesty-perception. While Study 1 failed to report a positive effect and Study 2 found a marginal effect only, here it did emerge. The potential reasons for this are tackled later in Discussion and conclusions. Thus, the perceptual dimensions bearing relevance for prosocial status signaling showed positive results. Moreover, 
on the average, the donations promised to the presumed users of organic foods were higher $\left(M_{\text {user }}\right.$ $=10.70 €$, S.D. $=13.60)$ than those promised to the presumed non-users $\left(M_{\text {user }}=7.90 €\right.$, S.D. $=$ 12.00; $\mathrm{U}=11835, p=.01, d=0.22)$.

\section{Table II.}

The effect of organic label vs. no label on t-shirt on forming consumer image

\begin{tabular}{|l|ll|lc|}
\hline \multirow{2}{*}{ Image dimension } & \multicolumn{2}{|c|}{ No label condition $(\mathrm{N}=168)$} & \multicolumn{2}{c|}{ Organic label condition $(\mathrm{N}=168)$} \\
& Mean & S.D. & Mean & S.D. \\
\hline Altruism & $4.31^{\mathrm{a}}$ & 0.89 & $4.56^{\mathrm{b}}$ & 0.87 \\
\hline Status & $4.51^{\mathrm{a}}$ & 1.22 & $4.79^{\mathrm{b}}$ & 0.92 \\
\hline Honesty & $4.83^{\mathrm{a}}$ & 1.02 & $5.06^{\mathrm{b}}$ & 0.92 \\
\hline
\end{tabular}

Means with different superscript letters differ significantly at $p<.05$.

A logical next step in testing $\mathrm{H} 3$ was to conduct a multiple regression analysis to see if the status, altruism and honesty perceptions mediate the effect of prosocial status signaling on charity donation behaviors. This included using Preacher and Hayes's (2008) methodology, with 5,000 bootstrap resamples, to describe the confidence intervals of the indirect effects. The results confirmed the direct effect of favoring organic food (as opposed to nonfavoring) on charity donations $(\beta=2.80, t(334)=2.00, p=.05)$. However, this direct effect became nonsignificant after entering the perceptions of status $(\beta=.59 ; \mathrm{CI}=.14$ to 1.37$)$, altruism $(\beta=.49 ; \mathrm{CI}=.07$ to 1.29$)$ and honesty $(\beta=.37 ; \mathrm{CI}=.01$ to 1.04$)$ as predictors $(\beta=2.21, t(334)$ $=1.59, p=.11 ; \beta=2.32, t(334)=1.66, p=.08 ; \beta=2.45, t(334)=1.74, p=.10$, respectively $).$ In summary, then, these analyses confirmed the indirect effect of favoring organic food (as opposed to non-favoring) on observing consumers' charity donation behavior. This effect materialized via the elevated status, altruism and honesty perceptions (see Figure 2). 

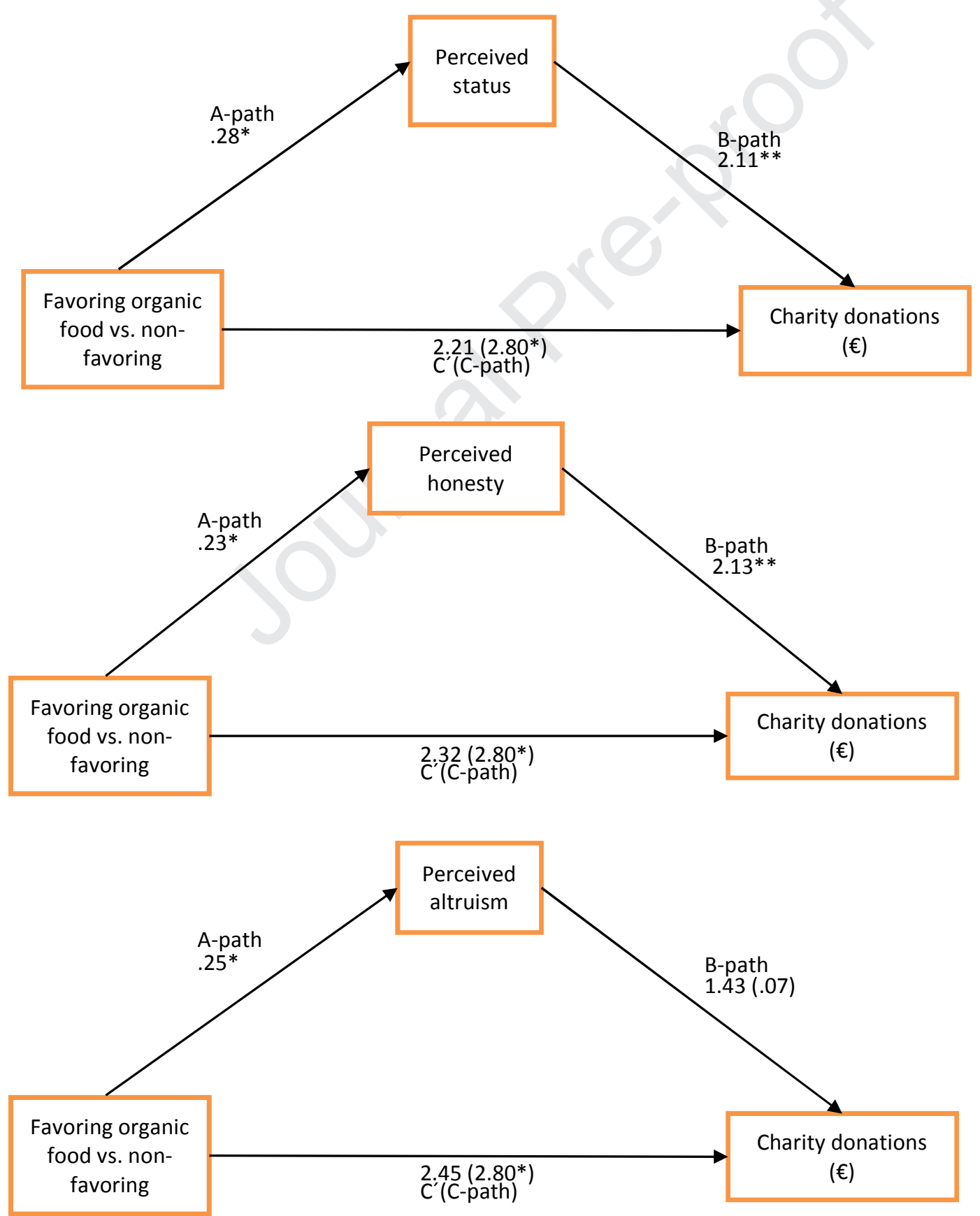
$*=p<.05 ; * *=p<.01$

\section{Figure 2.}

Perceived status, honesty and altruism mediate the effect of prosocial signaling on giving to charity

To conclude, the image effects reported in Studies 1 and 2 to a large extent reemerge, even though the methodology employed purported to evoke a less conscious consumer impression formation process. Moreover, participants expressed more benevolent behaviors toward the consumers assumed to favor organic foods. This impact was driven by observers' enhanced status, altruism and honesty perceptions of organic food users. Thus, the habitual use of organic foods appears to fulfill the fourth criterion of a costly signal as well.

\section{Discussion and conclusions}

To conclude, this research advances the current understanding concerning the interlinkages between organic food usage, prosocial status signaling and consumer impressions. Three novel research hypotheses were developed and tested (see Table 3). Organic food users were explicitly seen as more altruistic, status-laden and honest (reasonable support for Hypothesis 1). Weaker support could be ascertained for the idea that observers' values moderate the perception of organic food users (Hypothesis 2). Nevertheless, consumers embracing conservative values did view organic food users in a more altruistic light. Perceptual benefits accrue for organic food users also when observers' images are formed more implicitly (again supporting Hypothesis 1). Further, the idea that organic food users are more benevolently treated in social interaction by 
prosocial signal observers (Hypothesis 3) was moderately well substantiated. Thus, in summary, organic food consumption behaviors can indeed serve as a prosocial status signal.

Table III.

Assessing the empirical evidence for the tested hypotheses

\begin{tabular}{|c|c|c|c|c|}
\hline & Study 1 & Study 2 & Study 3 & $\begin{array}{l}\text { Overall assessment } \\
\text { of acceptance }\end{array}$ \\
\hline $\begin{array}{c}\text { Hypothesis 1: } \\
\text { "Those consumers } \\
\text { who signal about their } \\
\text { habit of favoring } \\
\text { organic foods are } \\
\text { perceived as more } \\
\text { altruistic, status-laden } \\
\text { and honest than } \\
\text { consumers who do } \\
\text { not." }\end{array}$ & $\begin{array}{c}\text { - Supporting evidence: } \\
\text { users of organic ketchup, } \\
\text { bacon and coffee were } \\
\text { explicitly perceived as } \\
\text { more altruistic and status- } \\
\text { laden } \\
\text { - Refuting evidence: users } \\
\text { of organic ketchup, bacon } \\
\text { and coffee were not } \\
\text { explicitly perceived as } \\
\text { more honest }\end{array}$ & $\begin{array}{l}\text { - Supporting evidence: } \\
\text { generic users of organic } \\
\text { foods were explicitly } \\
\text { perceived as more } \\
\text { altruistic, status-laden } \\
\text { and honest }\end{array}$ & $\begin{array}{l}\text { - Supporting evidence: } \\
\text { users of organic foods were } \\
\text { implicitly perceived as } \\
\text { more altruistic, status-laden } \\
\text { and honest }\end{array}$ & $\begin{array}{l}\text { - Reasonable support for } \\
\text { acceptance }\end{array}$ \\
\hline $\begin{array}{l}\text { Hypothesis 2: } \\
\text { "Observing } \\
\text { consumers' self- } \\
\text { transcendent and } \\
\text { conservative values } \\
\text { positively moderate } \\
\text { the extent to which } \\
\text { organic food users are } \\
\text { viewed as altruistic, } \\
\text { status-laden and } \\
\text { honest." }\end{array}$ & - Not tested & $\begin{array}{l}\text { - Supporting evidence: } \\
\text { conservative values } \\
\text { moderated observers' } \\
\text { perception of altruism of } \\
\text { users of organic foods } \\
\text { - Refuting evidence: } \\
\text { self-transcendent values } \\
\text { did not moderate } \\
\text { observers' perception of } \\
\text { users of organic foods }\end{array}$ & - Not tested & $\begin{array}{l}\text { - Conditional support for } \\
\text { acceptance }\end{array}$ \\
\hline $\begin{array}{l}\text { Hypothesis 3: } \\
\text { "Those consumers } \\
\text { who signal about their } \\
\text { habit of favoring } \\
\text { organic foods are } \\
\text { nonconsciously } \\
\text { perceived as more } \\
\text { altruistic, status-laden } \\
\text { and honest as well as, } \\
\text { consequently, more } \\
\text { positively treated in } \\
\text { social interactions } \\
\text { than consumers who } \\
\text { do not." } \\
\end{array}$ & - Not tested & - Not tested & $\begin{array}{l}\text { - Supporting evidence: } \\
\text { users of organic foods were } \\
\text { more positively treated in } \\
\text { social interaction and this } \\
\text { effect was mediated by } \\
\text { elevation in how they were } \\
\text { perceived by observers }\end{array}$ & $\begin{array}{l}\text { - Moderate support for } \\
\text { acceptance }\end{array}$ \\
\hline
\end{tabular}


This research spurs numerable implications and future research suggestions. These will be tackled in the following; starting with an elaboration of the theoretical contributions of the conducted research.

\subsection{Theoretical implications}

Research conducted here demonstrates the ability of organic food favoring to act as prosocial status signaling. By the same token, this endeavor advances theory building. First, in addition to evolutionary theory of costly signaling, conceptualizations from social psychology (the continuum model of consumer impression formation) and cultural research (symbolic consumption) were harnessed to produce three hypotheses. This is a response to the call for working towards the synthesis of evolutionary and sociocultural accounts to better understand human and consumer behavior (Lewis, Al-Shawaf, Conroy-Beam, Asao, \& Buss, 2017; Malovicki-Jaffe, McDonald, Halperin, \& Saguy, 2018). On the basis of new theorizing, three key image qualities (altruism, status, honesty) vital for a prosocial status signal were identified and

organic food symbolism was linked to them. Moreover, factors affecting the formation of (non)conscious images of organic food users in the minds of observing consumers were considered. To go beyond the conventional perceptual responses as DVs, a fresher idea was theoretically argued for: that favoring organic food can also nonconsciously invoke benevolent behaviors from others toward this prosocial status signaler or message sender.

Second, the moderators of the process whereby consumers form an image of organic food users have so far been poorly recognized, conceptualized and empirically verified. This study enriches the understanding of how individual variation within observers affects the way they sense and interpret (prosocial) status symbols - a theme that has been afforded a high priority on 
future research agendas (Anderson et al., 2015). More precisely, establishing a conceptual linkage between observing consumers' self-transcendent and conservative values and the way in which organic food users are perceived represents an extension to existing literature concerning prosocial status signaling. This forwards the aspiration of Berger (2017), who urges researchers on the topic to take account the characteristics of observers, especially their social status. Logically, considering observing consumers' value preferences, since they define what is appreciated in a given society and what is not, qualifies as a step toward that direction.

Not all of the abovementioned conceptual openings received unequivocal empirical support. To illustrate, Study 3 found positive results for all of the prosocial status signal perceptions (altruism, status, honesty), but Studies 1 and 2 only for altruism and status (in S2, a marginal effect for honesty was detected). Many factors can explain this. The differences in the measurement items (sincere vs. trustworthy \& honest), scale use (semantic differential vs. Likert) and logic (explicit vs. implicit) can play a role here. It is challenging to take a stand on whether the honesty-perception results of Studies $1 \& 2$ or Study 3 are more reliable. On the whole, the scale, perhaps, leans more toward the latter as the findings of Study 3 more fully converge with the theorizing presented. Moreover, it can be argued that wearing a t-shirt with an organic logo on it vs. using organic foods regularly qualifies as a stronger identity-signaling device (cf. Chan et al., 2012) - magnifying observers' honesty perception.

Unexpected findings also surfaced: Why did observers' conservative values positively moderate the formation of an altruism-image of a user of organic foods while self-transcendent values did not? This specific finding cannot be easily explained by the consumer value/product symbolism (in)congruity account cited in Section 2.3 - it is too general to identify the detailed drivers of alternative positive value moderations. Why would the perceived (in)congruency 
between conservative observers' values (safety, tradition, conformity) and symbolic meanings conveyed by apparent organic favorers (e.g. health, security) increase the likelihood of them being viewed as more altruistic in particular? Fortunately, the social comparison theory offers another way to understand this as it is applicable to making sense of how consumers are influenced by others' product or brand choice behaviors (Dahl, Argo, \& Morales, 2012). According to Schwartz's value circumplex, at the outset, a conservative value base (safety, tradition, conformity) can be characterized as less altruistic than a self-transcendent value base (universalism, benevolence). Hence, if a conservative consumer observes someone favoring organic foods, then an upward social comparison process is likely to be initiated (Argo, White, \& Dahl, 2006), because this behavior is imbued with prosocial symbolism (as the results of this research shows) that, in turn, can be regarded as virtuous or desirable in many western societies at the moment. This can lead to the heightened altruism-perception. In contrast, the process of upward social comparison probably does not even start in the case of a self-transcendent consumer observing others to favor organic foods because their sustainability or "prosociality" standards are already at a high level. Thus, noticing a consumer favoring organic foods does not impress them to the extent that they would raise their altruism evaluation of this person. These ideas receive credence from Laureati et al. (2013), who found that the taste evaluations of "sustainability-conscious" did not differ between the yogurt samples informed to be organic vs. conventional - yet, a positive effect emerged for the "sustainability-non-conscious."

These complications in the relationship between the conceptual reasoning and empirical reality tell about the ambiguity underlying the phenomenon of prosocial status signaling. Even if they remain partially unsolved, the present research both theoretically and substantively furthers 
the extant body of knowledge. Naturally, more contributions are needed from other consumer scholars.

\subsection{Future research suggestions}

In this research, the key finding that organic foods can serve as a prosocial status signal has mainly been explained in terms of the evolutionary theory of sexual selection (costly signaling). Even though it has been successfully applied in business research (e.g., Lee et al., 2015), it may be imperfect for understanding how consumption behaviors such as favoring organic food serve reputation management and coalition formation within social networks devoid of mating concerns. The notion of indirect reciprocity (Wu, Balliet, \& Van Lange, 2016) provides an alternative evolutionary conceptualization for understanding prosocial status signaling occurring through favoring of organic foods. Its underlying principle is that a member of a human social network can gain a good reputation by behaving altruistically - and receive indirect benefits later from the third parties of the network. New neuroscientific research suggests that reputation is a unique human mediator of altruistic behavior and that detectable specific brain activity is associated with its management (Izuma, 2012). In their application of the indirect reciprocity theory, Wu et al. (2016) found that people increase their generosity when the recipient is believed to be socially well-connected - possessing a great potential for gossiping. This lens enables a reinterpretation of the key result: Perceiving organic food users as altruistic and honest evokes a belief that they also possess an influential position (cf. status) in the social network. This is why it makes evolutionary sense to treat them nicely - after all, they probably tell about it to others in the network, and this in turn enhances the observers' own reputation. The viability of 
these two evolutionary accounts in advancing the understanding of prosocial status signaling should be addressed.

Another, non-evolutionary, general framework that can be harnessed to tackle prosocial status signaling through favoring organic food is offered by the equity theory. Ross and Kapitan (2018) claim that the motivating force behind prosocial consumption is how much consumers perceive they have given to, and gotten from, the marketplace. This idea enables a proposal that at the outset, organic food users, when seemingly unnecessarily sacrificing their own resources (green products are more expensive and less readily available) for the collective interest, put themselves in the imbalanced position - they give more to the marketplace than they get from it. However, this imbalance can be equaled out by the reputational benefits organic food users reap from those consumers who observe their virtuous prosocial behaviors - and both perceive and treat them positively.

Acknowledgement of other possible moderators is one more important theoretical implication. For example, gender can play a role, even though it could not be established in the studies presented here. On the basis of a study by Roux, Tafani and Vigneron (2017), women observers can perceive prosocial status signalers as more refined (e.g., elegant, attractive, magical) while men observers can view them as more elite-hungry (e.g., successful, selective, prestigious) and exclusive (e.g., distinguishable, uncommon, original). Yet, Shang and Peloza (2016) have uncovered how both men and women are more likely to consume ethically in the presence of observers of the opposite sex. Beyond values, other psychological characteristics such as narcissism qualify as potential moderators. According to Naderi and Strutton (2015), narcissists are inclined to purchase more expensive green products due to the prestigious and luxurious image they confer to others. Self-monitoring and need for uniqueness represent 
additional factors that can have a moderating impact (Yang, Chartrand, Fitzsimons, 2015; Bellezza et al., 2014). Even observers' genomes can play a role, as the heritability of prosocial traits can be as high as 69\% (Israel, Hasenfratz, \& Knafo Noam, 2015).

Thus, there is a need for additional theoretical approaches and conceptual elaboration concerning the phenomenon of prosocial status signaling generally and organic food consumption as one of its manifestations specifically. The ideas outlined above should help other researchers to take further steps.

\subsection{Study limitations}

As always, no research is perfect and a few limitations can be identified. At the same time, they represent additional opportunities for future studies.

First, the studies fall short of definitely determining whether the images of users of organic foods or more generally of prosocially behaving consumers are formed predominantly consciously vs. nonconsciously or in tandem. In the real-world consumption contexts, less conscious image formation is more likely. The implicit effects of environmental cues on consumer behavior have been documented (Berger \& Fitzsimons, 2008). Incidentally witnessing a fellow consumer choosing an organic food item in a store exemplifies how an observer's image of him/her can be nonconsciously shaped. In any case, more investigations are mandatory to disentangle the effects of conscious and nonconscious mechanisms on prosocial status signaling and creation of consumer images.

Second, the data sets were collected within the same metropolitan area from samples that are not fully representative of the general population. However, even though student convenience samples (Study 1) do not provide generalizable results, they are homogenous in terms of 
demographic background variables such as age and income, as they do not vary dramatically within student populations - contributing to the internal validity of the test of a conceptual idea (Peterson \& Merunka, 2014, p. 1036). As the symbolic meanings attached to eating generally or to natural foods specifically can be shaped by the sociocultural context in which the signal senders and receivers are embedded (see, e.g., Luomala, Sirieix, \& Tahir, 2009; Kooijmans \& Flores-Palacios, 2014), caution must be exercised when generalizing the findings beyond Western urban consumption environments and populations. Indeed, Puska, Kurki, Lähdesmäki, Siltaoja, and Luomala (2016) garnered evidence that even in a relatively culturally homogenous Western country, organic food users are perceived and socially treated differently in urban and rural regions. Thus, more observations should be collected from various sociocultural contexts and populations to cross-check the validity of the results of this research.

Third, it is possible that in spite of the safeguards (filler items) put in place in Study 3, asking about altruism, status and honesty perceptions primed the participants and consequently influenced the amount of money they expressed they would be willing to donate. While this explanation cannot be definitively ruled out, one has to remember that this would have occurred in both of the conditions (no label vs. organic label on t-shirt) and thus would not alone account for the differences found between the experimental groups. Moreover, Lee et al. (2015, Experiment 1) followed the same order of presenting the questions (image perceptions $\rightarrow$ preferential social treatment), with nonsignificant results discovered for the latter.

Fourth, the results were produced using only one form of prosocial status signaling. The degree to which its other manifestations - such as habitual consumption of fair trade (Kimura et al., 2012) or local foods (Memery et al., 2015) or even consuming less (Brooks \& Wilson, 2015) - function in the same way remains yet another open question. 


\subsection{Managerial implications}

First, the central finding that observers perceive organic food users as respected, altruistic and honest and treat them more favorably in social interaction has managerial relevance. Obviously, the creative use of these meanings in marketing communication of organic foods is likely to yield more optimal market response. A more intriguing and less apparent implication for food retailers is to employ in-store marketing devices (e.g. short videos on digital displays) to portrait a gallery of organic food users - potentially triggering the activation of store patrons' altruism-, status- and honesty-perceptions. In turn, this may instigate the feelings of admiration or envy and raise the possibility of emulative consumer behaviors (Antonetti \& Maklan, 2016). In fact, as the findings of Study 3 show, an unconscious benevolent behavioral tendency or what Chernev and Blair (2015) call as the benevolence halo may be evoked and lead to generalizing consequences. Namely, the products typically considered as prosocial or virtuous (e.g. fair trade, local, climate-compensated or healthy foods) can then not only be viewed favorably, but also behaviorally approached because they are thought to represent the likely choices organic food users also. This could increase the overall sales of sustainable and wellbeing-promoting goods a triple win for society, consumers and food industry.

Second, the results concerning the moderating role of observer values invoke the idea of tailoring the marketing efforts to maximally appeal to various consumer segments. To illustrate, for consumers embracing conservative values, organic foods could be promoted for their safety, healthiness, and righteousness. Indeed, as regards healthiness, the study by Sihvonen and Luomala (2017) actually demonstrates that a health goal-priming message more effectively promotes leaner food choices for consumers with strong (vs. weak) conservative values. In 
stores, the products could be placed among conventional ones and the packages should probably not feature overly conspicuous "organic" messaging. This would encourage the image of organic foods as a conformist and mainstream alternative. In turn, advertising for this value segment could highlight that choosing organic food products helps to maintain social order and cherish traditions.

\section{REFERENCES}

Aaker, J. L. (1997). Dimensions of brand personality. Journal of Marketing Research, 34(3), 347-356.

Aertsens, J., Verbeke, W., Mondelaers, K., \& Huylenbroeck, G. (2009). Personal determinants of of organic food consumption: A review. British Food Journal, 111(10), 1140-1167.

Allen, M. W., Gupta, R., \& Monnier, A. (2008). The interactive effect of cultural symbols and human values on taste perception. Journal of Consumer Research, 35(2), 294-308.

Anderson, C., Hildreth, J. A. D., \& Howland, L. (2015). Is the desire for status a fundamental motive? A review of the empirical literature. Psychological Bulletin, 141(3), 574-601.

Antonetti, P., \& Maklan, S. (2016). Hippies, greenies, and tree huggers: How the "warmth" stereotype hinders the adoption of responsible brands. Psychology \& Marketing, 141(10), 796-813. 
Argo, J. J., White, K., \& Dahl, D. W. (2006). Social comparison theory and deception in interpersonal exchange of consumption information. Journal of Consumer Research, 33(1), 99-108.

Bauer, H. H., Heinrich, D., \& Schäfer, D. B. (2013). The effects of organic labels on global, local, and private brands: More hype than substance? Journal of Business Research, 66(8), 1035-1043.

Bellezza, S., Gino, F., \& Keinan, A. (2014). The red sneakers effect: Inferring status and competence from signals of nonconformity. Journal of Consumer Research, 41(1), 35-54.

Bereczkei, T., Birkas, B., \& Kerekes, Z. (2010). Altruism towards strangers in need: Costly signaling in an industrial society. Evolution and Human Behavior, 31(2), 95-103.

Berger, J. (2017). Are luxury brand labels and "green" labels costly signals of social status? An extended replication. PLOS ONE 12(2): e0170216. doi:10.1371/journal.pone.0170216.

Berger, J., \& Fitzsimons, G. (2008). Dogs on the street, Pumas on your feet; How cues in the environment influence product evaluation and choice. Journal of Marketing Research, 45(1), $1-14$.

Berger, J., \& Shiv, B. (2011). Food, sex and hunger for distinction. Journal of Consumer Psychology, 21(4), 464-472.

Berman, J. Z., Levine, E. E., Barasch, A., \& Small, D. A. (2015). The braggart's dilemma: On the social rewards and penalties of advertising prosocial behavior. Journal of Marketing Research, 52(1), 90-104.

Bliege Bird, R., \& Smith, E. A. (2005). Signaling theory, strategic interaction, and symbolic capital. Current Anthropology, 46(2), 221-248.

Botonaki, A., \& Mattas, K. (2010). Revealing the values behind convenience food 
consumption”, Appetite, 55(3), 629-638.

Brasel, S. A., \& Gips, J. (2011). Red Bull "gives you wings" for better or worse: A double-edged impact of brand exposure on consumer performance. Journal of Consumer Psychology, 21(1), 57-64.

Brooks, J. S., \& Wilson, C. (2015). The influence of contextual cues on the perceived status of consumption-reducing behavior. Ecological Economics, 117(9), 108-117.

Brough, A. R., Wilkie, J. E. B., Ma, J., Isaac, M.S., \& Gal, D. (2016). Is eco-friendly unmanly? The green-feminine stereotype and its effect on sustainable consumption. Journal of Consumer Research, 43(4), 567-582.

Bryla, P. (2016). Organic food consumption in Poland: Motives and barriers. Appetite, 46(2), 737-746.

Bublitz, M. G., Peraccio, L. A., \& Block, L. G. (2010). Why did I eat that? Perspectives on food decision making and dietary restraint. Journal of Consumer Psychology, 20(3), 239-258.

Caracciolo, F., Cicia, G., Del Giudice, T., Cembalo, L., Krystallis, A., \& Grunert, K. G. (2016). Human values and preferences for cleaner livestock production. Journal of Cleaner Production, 112(1), 121-130.

Cavanaugh, L. A., Bettman, J. R., \& Luce, M. F. (2015). Feeling love and doing more for distant others: Specific positive emotions differentially affect prosocial consumption. Journal of Marketing Research, 52(5), 657-673.

Cervellon, M.-C., \& Shammas, L. (2013). The value of sustainable luxury in mature markets: A customer-based approach. Journal of Corporate Citizenship, 13(52), 90-101.

Chan, C., Berger, J., \& van Boven L. (2012). Identifiable but not identical: Combining social identity and uniqueness motives in choice. Journal of Consumer Research, 39(3), 561-573. 
Chernev, A., \& Blair, S. (2015). Doing well by doing good: The benevolent halo of corporate social responsibility. Journal of Consumer Research, 41(6), 1412-1425.

Costa, S., Zepeda, L., \& Sirieix, L. (2014). Exploring the social value of organic food: A qualitative study in France. International Journal of Consumer Studies, 38(3), 228-237.

Dahl, D. W., Argo, J. J., \& Morales, A. C. (2012). Social information in the retail environment: The importance of consumption alignment, referent identity, and self-esteem. Journal of Consumer Research, 38(5), 860-871.

Dean, M., Raats, M. M., \& Shepherd, R. (2008). Moral concerns and consumer choice of fresh and processed organic foods. Journal of Applied Social Psychology, 38(8), 2088-2107.

De Boer, J., Hoogland, C. T., \& Boersema, J. J. (2007). Towards more sustainable food choices: Value priorities and motivational orientations. Food Quality and Preference, 18(7), 985-996.

Delgado, M. S., Harriger, J. L., \& Khanna, N. (2015). The value of environmental status signaling. Ecological Economics, 111(1), 1-11.

De Nardo, M., Brooks, J. S., Klinsky, S., \& Wilson, C. (2017). Social signals and sustainability: Ambiguity about motivations can affect status perceptions of efficiency and curtailment behaviors. Environment Systems and Decisions, 37(2), 184-197.

Dreezens, E., Martijn, C., Tenbült, P., Kok, G., \& De Vries, N. K. (2005). Food and values: An examination of values underlying attitudes towards genetically modified and organically grown food products. Appetite, 44(1), 115-112.

Dubois, D., Rucker, D. D., \& Galinsky, A. D. (2012). Super size me: Product size as a symbol of status. Journal of Consumer Research, 38(6), 1047-1062.

Duclos, R., \& Barasch, A. (2014). Prosocial behaviors in intergroup relations: How donor selfconstrual and recipient group-membership shape generosity. Journal of Consumer Research, 
41(1), 93-108.

Eckhardt, G. M., Belk, R. W., \& Wilson, J. A. J. (2015). The rise of inconspicuous consumption. Journal of Marketing Management, 31(7-8), 807-826.

Elliott, R. (2013). The taste for green: The possibilities and dynamics of status differentiation through "green" consumption. Poetics, 41(3), 294-322.

Ellison, B., Duff, B .R. L., Wang, Z., \& Barnett White, T. (2016). Putting the organic label in context: Examining the interactions between the organic label, product type and retail outlet. Food Quality and Preference, 49(4), 140-150.

Goffman, E. (1951). Symbols of social status. The British Journal of Sociology, 2(4), 294-304.

Fehrler, S., \& Przepiorka, W. (2013). Charitable giving as a signal of trustworthiness: Disentangling the signaling benefits of altruistic acts. Evolution and Human Behavior, 34(1), $139-145$

Fennis, B. S., \& Pruyn, A. T. H. (2007). You are what you wear: Brand personality influences on consumer impression formation. Journal of Business Research, 60(6), 634-639.

Fiske, S. T., Lin, M., \& Neuberg, S. L. (1999). The continuum model - Ten years later. In S. Chaiken, \& Y. Trope (Eds.), Dual-Process Theories in Social Psychology (pp. 161-178). New York, USA: Guilford Press.

Fotopoulos, C., Krystallis, A., \& Pagiaslis, A. (2011). Portrait value questionnaire's (PVQ) usefulness in explaining quality food-related consumer behavior. British Food Journal, $113(2), 248-279$.

Griskevicius, V., Tybur. J. M., \& Van den Bergh, B. (2010). Going green to be seen: Status, reputation, and conspicuous conservation. Journal of Personality and Social Psychology, 98(3), 392-404. 
Griskevicius, V., Cantú S. M., \& van Vugt, M. (2012). The evolutionary bases for sustainable behavior: Implications for marketing, policy, and social entrepreneurship. Journal of Public Policy \& Marketing, 31(1), 115-128.

Hayes, A. F. (2017). Introduction to mediation, moderation, and conditional process analysis: A regression-based approach. New York, USA: Guilford Press.

Hamilton, W. D. (1964). The genetical evolution of social behavior. Journal of Theoretical Biology, 7(1), 17-52.

Han, Y. J., Nunes, J. C., \& Dréze, X. (2010). Signaling status with luxury goods: The role of brand prominence. Journal of Marketing, 74(4), 15-30.

Hemmerling, S., Hamm, U., \& Spiller, A. (2015). Consumption behavior regarding organic food from a marketing perspective - A literature review. Organic Agriculture, 5(4), 277-313.

Hwang, J. (2016). Organic food as self-presentation: The role of psychological motivation in older consumers' purchase intention of organic food. Journal of Retailing and Consumer Services, 28(1), 281-287.

Israel, S., Hasenfratz, L., \& Knafo Noam, A. (2015). The genetics of morality and prosociality. Current Opinion in Psychology, 5, 55-59.

Izuma, K. (2012). The social neuroscience of reputation. Neuroscience Research, 72(4), 283288.

Kafashan, S., Sparks, A., Griskevicius V., \& Barclay, P. (2014). Prosocial behavior and social status. In J. T. Cheng, J. L. Tracy, \& C. Anderson (Eds.), The Psychology of Social Status (pp. 139-158). New York, USA: Springer.

Kareklas, I., Carlson, J. R., \& Muehling, D. D. (2014). 'I eat organic for my benefit and yours': Egoistic and altruistic considerations for purchasing organic food and their implications for 
advertising strategists. Journal of Advertising, 43(1), 18-32.

Kent, R. (2007). Marketing Research. Approaches, Methods and Applications in Europe. London, UK: Thomson Learning.

Kihlberg, I., \& Risvik, E. (2007). Consumers of organic foods - value segments and liking of bread. Food Quality and Preference, 18(3), 471-481.

Kim, D., \& Jang, S. (2017). Symbolic consumption in upscale cafés: Examining Korean gen Y consumers' materialism, conformity, conspicuous tendencies and functional qualities. Journal of Hospitality \& Tourism Research, 41(2), 154-179.

Kimura, A., Mukawa, N., Yamamoto, M., Masura, T., Yuasa, M., Goto, S., Oka, T., \& Wada, Y. (2012). The influence of reputational concerns on purchase intention of fair-trade foods among young Japanese adults. Food Quality and Preference, 26(2), 204-210.

Kooijmans, A., \& Flores-Palacios, F. (2014). Is eating science or common sense? Knowledge about "natural foods" among self-identified "natural food" consumers, vendors and producers in rural and urban Mexico. Appetite, 81(1), 37-43.

Krystallis, A., Vassallo, M., Chryssohoidis, G. \& Perrea, T. (2008). Societal and individualistic drivers as predictors of organic purchasing revealed through a portrait value questionnaire (PVQ)-based inventory. Journal of Consumer Behaviour, 7(2), 164-187.

Larsen, G., Lawson, R., \& Todd, S. (2010). The symbolic consumption of music. Journal of Marketing Management, 26(7-8), 671-685.

Laureati, M., Jabes, D., Russo, V., \& Pagliarini, E. (2013). Sustainability and organic production: How information influences consumer's expectation and preference for yogurt. Food Quality and Preference, 30(1), 1-8.

Lea, E., \& Worsley, T. (2005). Australians' organic food beliefs, demographics and values. 
British Food Journal, 107(11), 855-689.

Lee, J., Ko, E., \& Megehee, C. M. (2015). Social benefit of brand logos in presentation of self in cross and same gender influence contexts. Journal of Business Research, 68(6), 1341-1349.

Lernoud, J., Potts, J., Sampson, G., Voora, V., Willer, H., \& Wozniak, J. (2015). The State of Sustainable Markets - Statistics and Emerging Trends. Geneva, Switzerland: International Trade Centre.

Lewis, D. M. G., Al-Shawaf, L., Conroy-Beam, D., Asao, K., \& Buss, D.M. (2017). Evolutionary psychology: A how-to guide. American Psychologist, 72(4), 353-373.

Lindeman, M., \& Verkasalo, M. (2005). Measuring values with the Short Schwartz's Value Survey. Journal of Personality Assessment, 85(2), 170-178.

Liu, F., Li, J., Mizerski, D., \& Soh, H. (2012). Self-congruity, brand attitude, and brand loyalty: A study on luxury brands. European Journal of Marketing, 46(7/8), 922-937.

Luomala, H. T., Sirieix, L., \& Tahir, R. (2009). Exploring emotional eating patterns in different cultures: Toward a conceptual framework model. Journal of International Consumer Marketing, 21(3), 231-245.

Machiels, C. J. A., \& Karnal, N. (2016). See how tasty it is? Effects of symbolic cues on product evalution and taste. Food Quality and Preference, 52(1), 195-202.

Malovicki-Yaffe, N., McDonald, M., Halperin, E., \& Saguy, T. (2018). God, sex and money among the ultra-Orthodox in Israel: An integrated sociocultural and evolutionary perspective. Evolution and Human Behavior, 39(6), 622-631.

Mazar, N., \& Zhong, C.-B. (2010). Do green products make us better people? Psychological Science, 21(4), 494-498.

Memery, J., Angell, R., Megicks, P., \& Lindgreen, A. (2015). Unpicking motives to purchase 
locally-produced food: analysis of direct and moderation effects. European Journal of Marketing, 48(7/8), 1207-1233.

Naderi, I., \& Strutton, D. (2015). I support sustainability but only when doing so reflects fabulously on me: Can green narcissists be cultivated? Journal of Macromarketing, 35(1), 7083.

Neel, R., Sadalla, E., Berlin, A., Ledlow, S., \& Neufield, S. (2014). The social symbolism of water-conserving landscaping. Journal of Environmental Psychology, 40(12), 49-56.

Nelissen, R. M. A., \& Meijers, M. M. C. (2011). Social benefits of luxury brands as costly signals of wealth and status. Evolution and Human Behavior, 32(35), 343-355.

Nelson Laska, M., Larson, N. I., Neumark-Szteiner, D., \& Story, M. (2012). Does involvement in food preparation track from adolescence to young adulthood and is it associated with better dietary quality? Findings from a ten-year longitudinal study. Public Health Nutrition, 15(7), $1150-1158$.

Noppers, E. H., Keizer, K., Bolderdijk, J. W., \& Steg, L. (2014). The adoption of sustainable innovations: Driven by symbolic and environmental motives. Global Environmental Change, $25(1), 52-62$.

Paasovaara, R., Luomala, H. T., Pohjanheimo, T., and Sandell, M. (2012). Understanding consumers' brand-induced food taste perception: A comparison of 'brand familiarity' - and 'consumer value-brand symbolism (in)congruity' - accounts. Journal of Consumer Behaviour, 11(1), 11-20.

Padilla Bravo, C. P., Cordts, A., Schulze, B., \& Spiller, A. (2013). Assessing determinants of organic food consumption using data form the German National Nutrition Study II. Food Quality and Preference, 28(1), 60-70. 
Park, J. K., \& Roedder John, D. (2014). I think I can, I think I can: Brand use, self-efficacy, and performance. Journal of Marketing Research, 52(2), 233-247.

Parker, B. T. (2009). A comparison of brand personality and brand-user imagery congruence. Journal of Consumer Marketing, 26(3), 175-184.

Peterson, R. A., \& Merunka, D. R. (2014). Convenience samples of college students and research reproducibility. Journal of Business Research, 67(5), 1035-1041.

Pohjanheimo, T., Paasovaara, R., Luomala H., \& Sandell, M. (2010). Food choice motives and bread liking of consumers embracing hedonistic and traditional values. Appetite, 54(1), 170180.

Preacher, K. J., \& Hayes, A. F. (2008). Asymptotic and resampling strategies for assessing and comparing indirect effects in multiple mediator models. Behavior Research Methods, 40(3), 879-891.

Puska, P., Kurki, S., Lähdesmäki, M., Siltaoja, M., \& Luomala, H. T. (2016). Male-male statussignaling through favoring organic foods in different socio-cultural contexts: Is the signaler perceived and treated as a friend or a foe? Psychology \& Marketing, 33(10), 843-855.

Puska, P., Kurki, S., Lähdesmäki, M., Siltaoja, M. \& Luomala, H. T. (2018). Sweet taste of prosocial status signaling: When eating organic foods makes you happy and hopeful. Appetite, 121(2), 348-359.

Puska, P., \& Luomala, H. T. (2016). Capturing qualitatively different healthfulness images of food products. Marketing Intelligence \& Planning, 34(5), 605-622.

Raghunathan, R., Walker-Naylor, R., \& Hoyer, W. D. (2006). The unhealthy = tasty intuition and its effects on taste inferences, enjoyment, and choice of food products. Journal of Marketing, 70(4), 170-184. 
Rana, J., \& Paul, J. (2017). Consumer behavior and purchase intention for organic food: A review and research agenda. Journal of Retailing and Consumer Services, 38(1), 157-165.

Ross, S. M., \& Kapitan, S. (2018). Balancing self/collective-interest: Equity theory for prosocial consumption. European Journal of Marketing, 52(3/4), 528-549.

Roux, E., Tafani, E., \& Vigneron, F. (2017). Values associated with luxury brand consumption and the role of gender. Journal of Business Research, 71(2), 102-113.

Saher, M., Arvola, A., Lindeman, M., \& Lähteenmäki, L. (2004). Impressions of functional food consumers. Appetite, 42(1), 79-89.

Sanders, M. S. (2010). Making a good (bad) impression: Examining the cognitive processes of disposition theory to form a synthesized model of media character impression formation. Communication Theory, 20(2), 147-168.

Schrank, Z., \& Running, K. (2018). Individualist and collectivist consumer motivations in local organic food markets. Journal of Consumer Culture, 18(1), 184-201.

Sexton, S. E., \& Sexton, A. L. (2014). Conspicuous conservation: The Prius halo and willingness to pay for environmental bona fides. Journal of Environmental Economics and Management, 67(3), 303-317.

Shang, J., \& Peloza, J. (2016). Can "real" men consume ethically? How ethical consumption leads to unintended observer inference. Journal of Business Ethics, 139(1), 129-145.

Sihvonen, J. \& Luomala, H. (2017). Hear what I appreciate: Activation of consumption motives for healthier food choices across different value segments. The International Review of Retail, Distribution and Consumer Research, 27(5), 502-514.

Soler, M. (2012). Costly signaling, ritual and cooperation: Evidence from Candomblé, an AfroBrazilian religion. Evolution and Human Behavior, 33(4), 346-356. 
Thogersen, J., Zhou, Y., \& Huang, G. (2016). How stable is the value basis for organic food consumption in China? Journal of Cleaner Production, 134(15), 214-224.

Van der Wal, A. J., van Horen, F., and Grinstein, A. (2016). The paradox of 'green to be seen': Green high-status shoppers excessively use (branded) shopping bags. International Journal of Research in Marketing, 33(1), 216-219.

Vartanian, L. R. (2015). Impression management and food intake: Current directions in research. Appetite, 86(3), 74-80.

Vartanian, L. R., Herman, J. P., \& Polivy, J. (2007). Consumption stereotypes and impression management: How you are what you eat. Appetite, 48(3), 265-277.

Vermeir, I., \& Verbeke, W. (2008). Sustainable food consumption among young adults in Belgium: Theory of planned behaviour and the role of confidence and values. Ecological Economics, 64(3), 842-853.

Wang, Y., \& Griskevicius, V. (2014). Conspicuous consumption, relationships, and rivals: Women's luxury products as signals to other women. Journal of Consumer Research, 40(5), 834-854.

Weiss, L., \& Venkataramani Johar, G. (2016). Products as self-evaluation standards: When owned and unowned products have opposite effects on self-judgment. Journal of Consumer Research, 32(6), 915-930.

Willer, R. (2009). Groups reward individual sacrifice: The status solution to the collective action problem. American Sociological Review, 74(1), 23-43.

Wu, J., Balliet, D., \& Van Lange, P. A. M. (2016). Reputation management: Why and how gossip enhances generosity. Evolution and Human Behavior, 37(3), 193-201.

Yang, L. W., Chartrand, T. L., \& Fitzsimons, G. J. (2015). The influence of gender and self- 
monitoring on the products consumers choose for joint consumption. International Journal of Research in Marketing, 32(4), 398-407.

\section{Appendix 1.}

Photos of product pairs (one example out of 6) and salad-makers used in the studies (conventional / no logo versions on left, organic / logo versions on right)
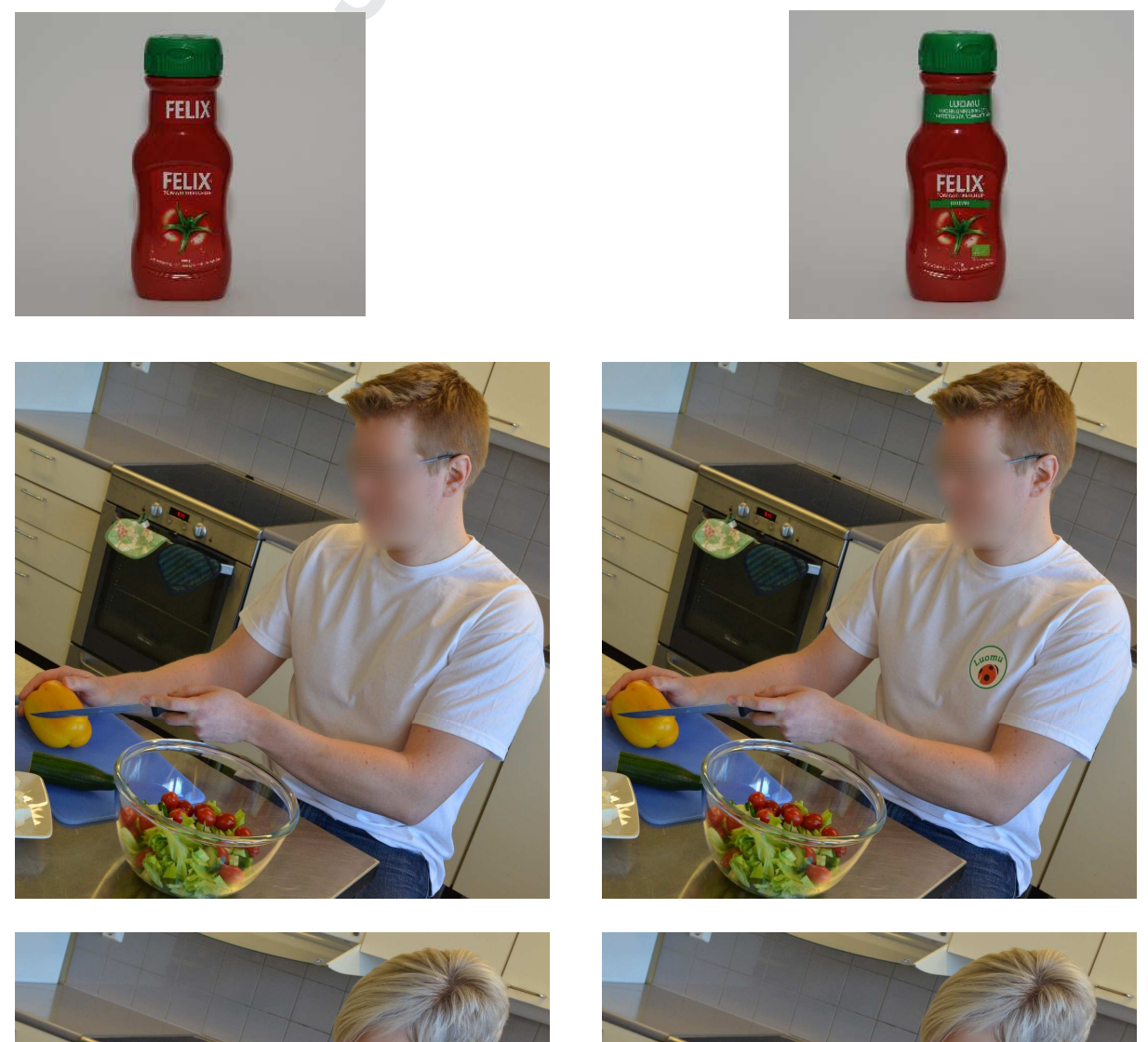


\section{Appendix 2.}

\section{Design details of Studies 1 and 2}

\begin{tabular}{|c|c|c|c|c|c|c|}
\hline Study 1 & Group $1(\mathrm{~N}=28)$ & Group $2(\mathrm{~N}=36)$ & Group $3(\mathrm{~N}=32)$ & Group $4(\mathrm{~N}=44)$ & Group $5(\mathrm{~N}=21)$ & Group $6(\mathrm{~N}=27)$ \\
\hline $\begin{array}{l}\text { Attributes } \\
\text { used to } \\
\text { measure } \\
\text { consumer } \\
\text { image } \\
\end{array}$ & \multicolumn{6}{|c|}{ 1) Altruism: unselfish-selfish; 2) Status: unsophisticated-sophisticated; 3) Honesty: fake-sincere } \\
\hline $\begin{array}{c}\text { Products } \\
\text { used to }\end{array}$ & $\begin{array}{l}\text { 1) Conventional } \\
\text { (brand A) ketchup }\end{array}$ & $\begin{array}{l}\text { 1) Organic (brand } \\
\text { A) ketchup }\end{array}$ & $\begin{array}{l}\text { 1) Conventional } \\
\text { (brand B) bacon }\end{array}$ & $\begin{array}{l}\text { 1) Organic (brand } \\
\text { B) bacon }\end{array}$ & $\begin{array}{l}\text { 1) Conventional } \\
\text { (brand C) coffee }\end{array}$ & $\begin{array}{l}\text { 1) Organic (brand } \\
\text { C) coffee }\end{array}$ \\
\hline $\begin{array}{c}\text { measure } \\
\text { consumer } \\
\text { image (user } \\
\text { imagery } \\
\text { approach) }\end{array}$ & \multicolumn{6}{|c|}{ 2) Brand X bananas (filler); 3) Brand X squeky cheese (filler); 4) Brand X roasted beef meat (filler) } \\
\hline $\begin{array}{l}\text { Number of } \\
\text { ratings per } \\
\text { respondent }\end{array}$ & \multicolumn{6}{|c|}{3 (image attributes) $\mathrm{x} 4$ (product items) } \\
\hline Study 2 & Group $1(\mathrm{~N}=43)$ & Group $2(\mathrm{~N}=40)$ & Group $3(\mathrm{~N}=44)$ & Group $4(\mathrm{~N}=44)$ & Group $5(\mathrm{~N}=44)$ & Group $6(N=44)$ \\
\hline $\begin{array}{l}\text { Attributes } \\
\text { used to } \\
\text { measure } \\
\text { consumer } \\
\text { image }\end{array}$ & \multicolumn{6}{|c|}{ 1) Altruism: unselfish-selfish; 2) Status: unsophisticated-sophisticated; 3) Honesty: fake-sincere } \\
\hline
\end{tabular}




\begin{tabular}{|c|c|c|c|c|c|c|}
\hline $\begin{array}{c}\text { Products } \\
\text { used to } \\
\text { measure } \\
\text { consumer } \\
\text { image (user } \\
\text { imagery } \\
\text { approach) }\end{array}$ & $\begin{array}{c}\text { 1) Conventional } \\
\text { (brand A) ketchup } \\
\text { 2) Conventional } \\
\text { (brand D) butter }\end{array}$ & $\begin{array}{c}\text { 1) Organic (brand } \\
\text { A) ketchup } \\
\text { 2) Organic (brand } \\
\text { D) butter }\end{array}$ & $\begin{array}{c}\text { 1) Conventional } \\
\text { (brand B) bacon } \\
\text { 2) Conventional } \\
\text { (brand E) yogurt }\end{array}$ & $\begin{array}{c}\text { 1) Organic (brand } \\
\text { B) bacon } \\
\text { 2) Organic (brand } \\
\text { E) yogurt }\end{array}$ & $\begin{array}{c}\text { 1) Conventional } \\
\text { (brand C) coffee } \\
\text { 2) Conventional } \\
\text { (brand F) canola } \\
\text { oil }\end{array}$ & $\begin{array}{c}\text { 1) Organic (brand } \\
\text { C) coffee } \\
\text { 2) Organic (brand } \\
\text { F) canola oil }\end{array}$ \\
\cline { 2 - 6 } & 3) Brand X bananas (filler); 4) Brand X squeky cheese (filler); 5) Brand X roasted beef meat (filler) \\
\hline $\begin{array}{c}\text { Number of } \\
\text { ratings per } \\
\text { respondent }\end{array}$ & 3 (image attributes) X 4 (product items) \\
\hline
\end{tabular}

